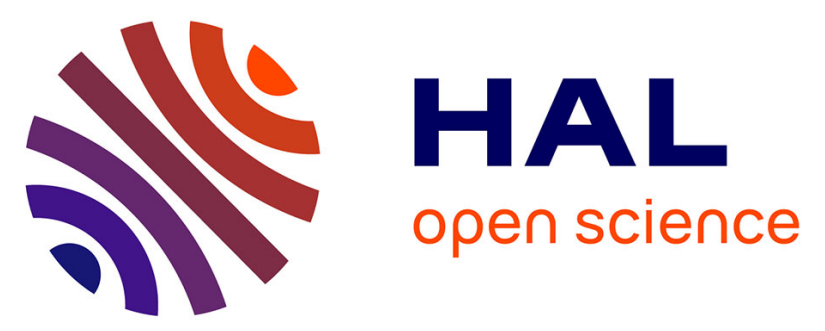

\title{
Liquid Phase Epitaxy growth, structure and spectroscopy of highly-doped 20 at.\% Yb3+:LiYF4 thin films
}

Gurvan Brasse, Pavel Loiko, Clara Grygiel, Abdelmjid Benayad, Franck

Lemarié, Viktor Zakharov, Andrey Veniaminov, Jean-Louis Doualan, A. Braud, Patrice Camy

\section{To cite this version:}

Gurvan Brasse, Pavel Loiko, Clara Grygiel, Abdelmjid Benayad, Franck Lemarié, et al.. Liquid Phase Epitaxy growth, structure and spectroscopy of highly-doped 20 at.\% Yb3+:LiYF4 thin films. Journal of Luminescence, 2021, 236, pp.118071. 10.1016/j.jlumin.2021.118071 . hal-03215588

\author{
HAL Id: hal-03215588 \\ https://hal.science/hal-03215588
}

Submitted on 7 Oct 2021

HAL is a multi-disciplinary open access archive for the deposit and dissemination of scientific research documents, whether they are published or not. The documents may come from teaching and research institutions in France or abroad, or from public or private research centers.
L'archive ouverte pluridisciplinaire HAL, est destinée au dépôt et à la diffusion de documents scientifiques de niveau recherche, publiés ou non, émanant des établissements d'enseignement et de recherche français ou étrangers, des laboratoires publics ou privés. 


\title{
Liquid Phase Epitaxy growth, structure and spectroscopy of highly- doped 20 at.\% $\mathrm{Yb}^{3+}: \mathrm{LiYF}_{4}$ thin films
}

Gurvan Brasse ${ }^{\mathrm{a}}$, Pavel Loiko ${ }^{\mathrm{a}}$, Clara Grygiel ${ }^{\mathrm{a}}$, Abdelmjid Benayad ${ }^{\mathrm{a}}$,

Franck Lemarie ${ }^{\mathrm{a}}$, Viktor Zakharov ${ }^{\mathrm{b}}$, Andrey Veniaminov ${ }^{\mathrm{b}}$, Jean-Louis

Doualan $^{\mathrm{a}}$, Alain Braud ${ }^{\mathrm{a}}$, and Patrice Camy, ${ }^{\mathrm{a}, *}$

${ }^{a}$ Centre de recherche sur les Ions, les Matériaux et la Photonique (CIMAP), UMR 6252

CEA-CNRS-ENSICAEN, Université de Caen Normandie, 6 Boulevard du Maréchal Juin, 14050 Caen Cedex 4, France

${ }^{b}$ ITMO University, 49 Kronverkskiy Pr., 197101 St. Petersburg, Russia

*Corresponding author, e-mail: patrice.camy@ensicaen.fr

\begin{abstract}
Highly doped (20 at.\%) $\mathrm{Yb}^{3+}: \mathrm{LiYF}_{4}$ single-crystalline thin films are grown on (001)-oriented bulk undoped $\mathrm{LiYF}_{4}$ substrates by Liquid Phase Epitaxy using lithium fluoride $(\mathrm{LiF})$ as a solvent. The growth temperature lies around 741 ${ }^{\circ} \mathrm{C}\left(0.5-1{ }^{\circ} \mathrm{C}\right.$ supercooling $)$ and the growth rate is $1.8-2.6 \mu \mathrm{m} / \mathrm{min}$. The singlecrystalline nature of the films is confirmed by X-ray diffraction and polarized Raman spectroscopy. The film morphology is studied and discussed. The polarized spectroscopic properties of $\mathrm{Yb}^{3+}$ ions are reported, indicating a stimulated-emission cross-section of $0.88 \times 10^{-20} \mathrm{~cm}^{2}$ at $993.9 \mathrm{~nm}$ in $\pi$-polarization and a radiation trapping free lifetime of the ${ }^{2} \mathrm{~F}_{5 / 2}$ state of $2.00 \mathrm{~ms}$ indicating weak concentrationquenching. The crystal-field splitting of $\mathrm{Yb}^{3+}$ multiplets is resolved at $12 \mathrm{~K}$. Highlydoped $\mathrm{Yb}^{3+}: \mathrm{LiYF}_{4} / \mathrm{LiYF}_{4}$ homoepitaxies are promising for waveguide and thindisk lasers at $\sim 1 \mu \mathrm{m}$.
\end{abstract}

Keywords: Liquid phase epitaxy; lithium yttrium fluoride; thin films; ytterbium ions; luminescence. 


\section{Introduction}

Lithium (rare earth) fluoride crystals with a general chemical formula of $\mathrm{LiLnF}_{4}$ (where $\mathrm{Ln}=\mathrm{Gd}, \mathrm{Y}$ or Lu is the host-forming cation) doped with trivalent laser-active rare-earth ions $\left(\mathrm{RE}^{3+}\right)$ are known for efficient laser emission in the near-infrared [1]. The LiLnF 4 crystals belong to the tetragonal crystal class (sp. gr. $I 4{ }_{1} / a$ ) and they have a scheelite-type ordered structure [2].

As host matrices, these crystals possess several advantages. First, they provide good thermo-mechanical properties such as high thermal conductivity (e.g., for $\mathrm{Yb}: \mathrm{LiYF}_{4}, \kappa_{\mathrm{a}}=4.1$ $\mathrm{W} / \mathrm{mK}$ and $\kappa_{\mathrm{c}}=5.2 \mathrm{~W} / \mathrm{mK}[3]$ ), weak anisotropy of thermal expansion and negative thermooptic coefficients $\mathrm{d} n / \mathrm{d} T$ leading to weak negative thermal lensing [4]. Second, they have attractive optical properties such as broad transparency range, low refractive indices and natural birefringence eliminating the depolarization losses (e.g., for $\mathrm{LiYF}_{4}, n_{\mathrm{o}}=1.449$ and $n_{\mathrm{e}}=1.471$ at $\sim 1 \mu \mathrm{m}$ [5]). Third, the low maximum phonon energies $\left(h v_{\mathrm{ph}}=446 \mathrm{~cm}^{-1}\right.$ for $\left.\mathrm{LiYF}_{4}\right)$ [6] reduce the probability of non-radiative (NR) relaxation for the excited-states of the $\mathrm{RE}^{3+}$ ions [7]. Finally, for the $\mathrm{RE}^{3+}$ doping, the $\mathrm{LiLnF}_{4}$ crystals offer a single substitutional rare-earth site and high available doping levels $[1,8]$. The Czochralski growth of bulk $\mathrm{LiLnF}_{4}$ crystals is also well developed [9].

The early studies focused mainly on $\mathrm{Nd}^{3+}$ doping of $\mathrm{LiYF}_{4}$ crystals [10]. Ytterbium $\left(\mathrm{Yb}^{3+}\right)$ ions, as compared to the $\mathrm{Nd}^{3+}$ ones, have greater potential for laser emission at $\sim 1 \mu \mathrm{m}$. $\mathrm{Yb}^{3+}$ (electronic configuration: $[\mathrm{Xe}] 4 \mathrm{f}^{13}$ ) has a simple energy-level scheme eliminating unwanted energy-loss processes such as excited-state absorption or energy-transfer upconversion. The inband pumping scheme results in high pump Stokes efficiency and reduced heat loading. The $\mathrm{Yb}^{3+}$ ions can be easily pumped by commercial InGaAs laser diodes emitting at $0.96 \mu \mathrm{m}$ [11].

Diode-pumped bulk Yb:LiYF 4 [11,12] and Yb:LiLuF 4 [13] lasers were reported. The possibility of laser operation with heavily $\mathrm{Yb}^{3+}$ doped crystals was demonstrated: a roomtemperature 30 at.\% $\mathrm{Yb}^{3+}$-doped $\mathrm{LiYF}_{4}$ laser generated a maximum peak power of $4.0 \mathrm{~W}$ at $1059 \mathrm{~nm}$ with a slope efficiency of 62.8\% [8]. Mode-locking of Yb:LiLnF4 oscillators was also realized [14-16]. Pirzio et al. reported on a SESAM mode-locked Yb:LiYF4 laser delivering 87 fs pulses at $\sim 1052 \mathrm{~nm}$ at a repetition rate of $100 \mathrm{MHz}$ [16]. A great improvement of the diodepumped laser performance was achieved under cryogenic temperatures [17]. Zapata et al. demonstrated a cryogenically cooled $(80 \mathrm{~K})$ diode-pumped $\mathrm{Yb}: \mathrm{LiYF}_{4}$ laser delivering an output power of $224 \mathrm{~W}$ at $995 \mathrm{~nm}$ with a slope efficiency of $68 \%$ and extremely low quantum defect [17]. These crystals were also considered for radiation cooling [18].

Besides bulk laser applications, the $\mathrm{LiYF}_{4}$ crystals are well suited for fabrication of $\mathrm{RE}^{3+}{ }_{-}$ doped single-crystalline thin films by Liquid Phase Epitaxy (LPE) [19]. Such active structures are of interest for waveguide lasers [20]. The growth, spectroscopy and efficient waveguide laser operation of $\mathrm{LiYF}_{4}$-based epitaxies doped with $\mathrm{Pr}^{3+}$ [21], $\mathrm{Yb}^{3+}$ [22], $\mathrm{Tm}^{3+}$ [23], $\mathrm{Ho}^{3+}$ [24] and $\mathrm{Nd}^{3+}[25]$ ions were reported. In particular, a 4 at.\% Yb, 5 at.\% Gd:LiYF $/ \mathrm{LiYF}_{4} \mathrm{LPE}-$ based waveguide laser generated $2.8 \mathrm{~W}$ at $1020 \mathrm{~nm}$ with a slope efficiency of $43 \%$ [22]. Note that the $\mathrm{Gd}^{3+}$ ions were added for the enhancement of the refractive index contrast between the substrate and the film. $\mathrm{RE}^{3+}$-doped $\mathrm{LiYF}_{4}$ thin films were also fabricated by Pulsed Laser Deposition (PLD) [26-27] and Matrix-Assisted Pulsed Laser Evaporation (MAPLE) [28]. 
Another possible application of LPE-grown crystalline thin films is their use in thin-disk lasers instead of the traditional technology which requires handling with thin (few hundreds of $\mu \mathrm{m})$ laser elements. This would require either high transition cross-sections for the $\mathrm{RE}^{3+}$ ions or high $\mathrm{RE}^{3+}$ doping levels. The latter condition can be easily satisfied in $\mathrm{Yb}^{3+}$-doped $\mathrm{LiYF}_{4}$. So far, efficient thin-disk lasers based on epitaxies doped with $\mathrm{Yb}^{3+}[30], \mathrm{Tm}^{3+}[31]$ and $\mathrm{Ho}^{3+}$ [32] ions were reported. Very recently, we achieved laser operation in highly $\mathrm{Tm}^{3+}$-doped (20 at.\%) $\mathrm{LiYF}_{4}$ thin films [33].

In the present work, we report for the first time on the LPE growth, structural and morphological characterization and detailed optical spectroscopy of highly-doped (20 at.\%) single-crystalline $\mathrm{LiY}_{1-\mathrm{x}} \mathrm{Yb}_{\mathrm{x}} \mathrm{F}_{4}$ thin films on oriented bulk $\mathrm{LiYF}_{4}$ substrates intended for the potential use in waveguide and thin-disk lasers.

\section{Elaboration of single-crystalline films}

LPE is very suitable for the growth of thick single-crystalline films onto bulk substrates of the same nature (this process is called homoepitaxy). It allows the growth of high optical grade epitaxial layers with a thickness lying between few $\mu \mathrm{m}$ and few hundreds of $\mu \mathrm{m}$. In the present work, the experimental process to get such layers consisted of the following steps: (i) the growth of undoped $\mathrm{LiYF}_{4}$ crystals by the Czochralski $(\mathrm{Cz})$ method, (ii) the orientation of the crystals and fabrication of the required oriented substrates for the epitaxial growth, (iii) the epitaxial growth of $\mathrm{Yb}^{3+}$-doped $\mathrm{LiYF}_{4}$ films onto the oriented substrates and (iv) preparation / shaping / polishing of the epitaxy to achieve the required dimensions and optical quality regarding the potential laser application.

\section{1. $\mathrm{Cz}$ growth of undoped $\mathrm{LiYF}_{4}$ single-crystals}

High optical quality undoped $\mathrm{LiYF}_{4}$ single crystals were grown by the $\mathrm{Cz}$ method. As raw materials, we used LiF (Alfa-Aesar, optical grade 99.5\%) and $\mathrm{Y}_{2} \mathrm{O}_{3}$ (Alfa Aesar, 4N-REO) following the molar ratio of $52 \% \mathrm{LiF}-48 \% \mathrm{YF}_{3}$, according to the related phase diagram of the $\mathrm{LiF}-\mathrm{YF}_{3}$ binary system [34], Fig. 1. The oxide precursor $\mathrm{Y}_{2} \mathrm{O}_{3}$ was fluorinated using a large excess of ammonium hydrogen bifluoride $\left(\mathrm{NH}_{4} \mathrm{HF}_{2}\right)$ solution under heating at $250{ }^{\circ} \mathrm{C}$, following the chemical equation:

$$
\mathrm{Y}_{2} \mathrm{O}_{3}+6 \mathrm{NH}_{4} \mathrm{HF}_{2} \rightarrow 2 \mathrm{YF}_{3}+6 \mathrm{NH}_{4} \mathrm{~F}+3 \mathrm{H}_{2} \mathrm{O}\left(T=250^{\circ} \mathrm{C}\right) .
$$

The dry cake obtained in this way needs to be annealed at $650{ }^{\circ} \mathrm{C}$ under a controlled argon atmosphere to remove the residual $\mathrm{NH}_{4} \mathrm{~F}$ and moisture. After synthesizing the required fluoride precursor $\mathrm{YF}_{3}$, the $\mathrm{Cz}$ growth of bulk $\mathrm{LiYF}_{4}$ was performed under an oxygen-free $\mathrm{Ar}$ atmosphere using a [001]-oriented seed of undoped $\mathrm{LiYF}_{4}$. The pulling rate was fixed at $1 \mathrm{~mm} / \mathrm{h}$. An example photograph of a $\mathrm{LiYF}_{4}$ boule is shown in Fig. 2(a).

The substrates were oriented along the (001) crystallographic plane because of the following reasons: (i) the growth direction of undoped $\mathrm{LiYF}_{4}$ crystal was along the [001] axis and, consequently, it was easier to prepare the substrates with better uniformity and optical 
quality in the orthogonal plane; (ii) due to isotropic thermo-mechanical properties of $\mathrm{LiYF}_{4}$ in the $\boldsymbol{a}-\boldsymbol{b}$ plane, it is easier to perform LPE.

Typically, substrates with transverse dimensions of $30 \times 11 \mathrm{~mm}^{2}$ and a thickness of 3.0 $\mathrm{mm}$ were used for the LPE process, so that bulk crystals grown by the $\mathrm{Cz}$ technique were around $60 \mathrm{~mm}$ in height and 30-40 $\mathrm{mm}$ in diameter. The substrates were finely polished on both faces and a special attention was paid concerning their flatness (measure to be $\lambda / 8$ ) and roughness of the polished surfaces (measured to be in the range of few $\mathrm{nm}$ ).

\subsection{Epitaxial growth of $\mathrm{Yb}: \mathrm{LiYF}_{4}$ single-crystalline layers}

The schematic of the LPE setup is described in detail in [20,35]. It can be divided into two main areas: the upper and bottom zones which are isolated from each other by an electrovalve. The upper area is an exchange airlock that allows for changing the samples, substrates and stirrer, while keeping the furnace in the proper temperature regime without contaminating the melt in the crucible located in the growth chamber. The glassy carbon crucible containing raw materials is installed in one-end-sealed silica tube which constitutes the growth chamber and is located in the heating zone of a tubular furnace where the thermal gradient is the lowest. The furnace has a dual heating zone that ensures a homogeneous temperature field through the whole height of the melt in the crucible and the temperature is controlled with a precision of $0.1{ }^{\circ} \mathrm{C}$. The growth of fluoride crystalline materials requires oxygen-free atmosphere of high purity.

In the case of $\mathrm{Yb}: \mathrm{LiYF}_{4}$ growth, the reagents are $\mathrm{LiF}$ (Alfa-Aesar, 99.5\%), $\mathrm{Y}_{2} \mathrm{O}_{3}$ and $\mathrm{Yb}_{2} \mathrm{O}_{3}$ (both Alfa Aesar, 4N-REO). The rare-earth oxides $\mathrm{Ln}_{2} \mathrm{O}_{3}(\mathrm{Ln}=\mathrm{Y}, \mathrm{Yb})$ are fluorinated according to the procedure described in Section 2.1 yielding $\mathrm{LnF}_{3}(\mathrm{Ln}=\mathrm{Y}, \mathrm{Yb})$ fluorides. The raw materials that compose the molten bath used for the LPE growth are taken according to the molar ratio $27 \%\left(\mathrm{YF}_{3}+\mathrm{YbF}_{3}\right)-73 \% \mathrm{LiF}$, in the manner to work at lower temperatures and to anticipate the vaporization of the LiF solvent, which will move the equilibrium on the phase diagram. The $\mathrm{Yb}^{3+}$ doping level is set to 20 at.\% with respect to $\mathrm{Y}^{3+}$, according to the formula $\mathrm{LiY}_{0.80} \mathrm{Yb}_{0.20} \mathrm{~F}_{4}$.

The fluorinated raw materials are introduced in the LPE growth chamber to be degassed under heating and then they are superheated to ensure good homogenization of the molten bath. An additional mechanical stirring of the $\mathrm{LiF}-\mathrm{YF}_{3}-\mathrm{YbF}_{3}$ mixture is also done.

A part of the phase diagram of the LiF-YF 3 binary system relevant for the LPE growth experiment is shown in Fig. 3. Our own studies confirm incongruent melting of $\mathrm{LiYF}_{4}$ with a peritectic molar composition about $49 \% \mathrm{YF}_{3}-51 \% \mathrm{LiF}$, in agreement with $[19,34]$. For the selected bath composition, $27 \%\left(\mathrm{YF}_{3}+\mathrm{YbF}_{3}\right)-73 \% \mathrm{LiF}$, the liquidus temperature was determined to be $\sim 744{ }^{\circ} \mathrm{C}$ with an uncertainty of about $3-4{ }^{\circ} \mathrm{C}$. This value agrees better with the phase diagram constructed by Thoma et al. [34]; the liquidus temperatures determined by Rogin et al. [19] seem overestimated. The apparent onset of crystallization (by visual observation) was approximately at $741.5^{\circ} \mathrm{C}$. The transition from dissolution to growth upon cooling was not very sharp (within a temperature range of about $1-1.5^{\circ} \mathrm{C}$ ).

After homogenizing of the bath, the temperature was slowly decreased just over the apparent onset of crystallization in a supersaturation regime and stabilized. After installing the 
substrate in the exchange airlock, the epitaxial growth process began by dipping the substrate into the molten bath. The growth temperature was set in the range of $741-740.5^{\circ} \mathrm{C}$ (i.e., the apparent supercooling was $0.5-1.0^{\circ} \mathrm{C}$ ). The substrate was rotated at a speed of $10 \mathrm{rev} / \mathrm{min}$ in the molten bath. The dipping duration varied between $20 \mathrm{~min}$ and 3 hours depending on the desired layer thickness, as well as on the particular temperature and viscosity of the bath. The mean growth rate estimated at a fixed dipping duration of $30 \mathrm{~min}$ amounted to $1.8 \pm 0.5 \mu \mathrm{m} / \mathrm{min}$ and $2.6 \pm 0.5 \mu \mathrm{m} / \mathrm{min}$ for $0.5{ }^{\circ} \mathrm{C}$ and $1{ }^{\circ} \mathrm{C}$ supercooling, respectively. This value accounts only for the uniform thickness of the $\mathrm{Yb}: \mathrm{LiYF}_{4}$ layer, i.e., when excluding the features of its bumpy surface and polycrystalline solvent residuals (see Section 4.1).

The obtained growth rates at a given supersaturation reasonably agree with the previous work of Rogin et al. where the bath composition of $40 \%\left(\mathrm{YF}_{3}+\mathrm{REF}_{3}\right)-60 \% \mathrm{LiF}$ was studied (i.e., located closer to the peritectic one). Thus, we can conclude that the growth mechanism of the layer is relying on attachment of new building units anywhere at the layer edge (in contrast to the regime of small supercoolings when this can happen only at kink positions). This growth mechanism provides higher growth rates which change almost linearly with increasing the apparent supercooling.

In our work, for obtaining high optical quality $\mathrm{Yb}: \mathrm{LiYF}_{4}$ layers, a relatively narrow range of growth temperatures (and, accordingly, apparent supercoolings) was used. Further increase of the supercooling to $3-5{ }^{\circ} \mathrm{C}$ resulted in higher growth rates albeit with lower control of the layer uniformity, thickness and formation of macroscopic defects (cracks) and appearance of polycrystalline material (a mixture of $\mathrm{Yb}: \mathrm{LiYF}_{4}$ and $\mathrm{LiF}$ ).

After removing the substrate from the molten bath, a smooth cooling ramp is applied to avoid crack formation in the grown layer [36]. A photograph of the as-grown $\mathrm{Yb}: \mathrm{LiYF}_{4} / \mathrm{LiYF}_{4}$ epitaxy is shown in Fig. 2(b). Approximately $2 / 3$ of the substrate contain the grown film which is separated from the non-dipped part of the substrate by the growth meniscus. The film is transparent, but its surface is covered by a white-colored residual crystallized solvent (LiF). It is easily removed by the top polishing of the layer.

\section{Experimental}

The surface morphology of the as-grown films was studied employing a confocal and interferometric optical microscope (Sensofar, S-neox) equipped with a blue light-emitting diode (LED, $\lambda=405 \mathrm{~nm}$ ) in the reflection mode. The surface roughness was studied in the confocal mode.

The polished end-facet of the epitaxy was studied using a confocal laser microscope (LSM 710, Carl Zeiss) equipped with a polarizer (P), an analyzer (A), and a blue GaN laser ( $\lambda$ $=405 \mathrm{~nm}$ ) in transmission mode. Two microscope objectives were used (one: $20 \times$, N.A. $=0.75$ and another: $50 \times$, N.A. $=0.95$ ).

The structure of the films was studied by single-crystal X-ray diffraction (XRD) using a Bruker AXS D8 Discover diffractometer with a four-circle goniometer, a line focus Cu X-ray source equipped with a Goebel mirror and a Ge (220) double-bounce monochromator providing a parallel and monochromatic $(\mathrm{Cu} \mathrm{K \alpha 1}, \lambda=0.15406 \mathrm{~nm})$ incident X-ray beam. A Ge (220) crystal analyzer was used to further limit the scintillator detector acceptance. Symmetric $2 \theta-\theta$ 
scans and reciprocal space maps (RSM) obtained by taking a series of $2 \theta-\omega$ patterns $\left( \pm 0.5^{\circ}\right.$ around the reference) at successive $\omega$ values $\left(\omega=\theta \pm \Delta ; \pm 0.5^{\circ}\right.$ around the reference) were recorded. For the RSM representation, the DxTools viewer [37] was used.

The composition of the films was studied by Energy Dispersive X-ray (EDX) spectroscopy using a scanning electron microscope (SEM, Jeol 6400). It was equipped with a tungsten filament thermoelectronic gun and a $10 \mathrm{~mm}^{2} \mathrm{X}$-microanalysis diode (Oxfordinstrument).

The polarized Raman spectra were measured with a Renishaw inVia confocal Raman microscope equipped with a half-wave $(\lambda / 2)$ plate and a polarizer $(\mathrm{P})$ using a Leica $\times 50$ objective $($ N.A. $=0.75)$. The excitation wavelength $\lambda_{\text {exc }}$ was $488 \mathrm{~nm}\left(\mathrm{Ar}^{+}\right.$laser line $)$.

First, the spectroscopic studies were performed at room temperature (RT, $293 \mathrm{~K}$ ). The absorption spectra were measured using a spectrophotometer (Lambda 1050, Perkin Elmer) and a Glan-Taylor polarizer. The luminescence spectra were measured using an optical spectrum analyzer (OSA, Ando AQ6315-E) and a Glan-Taylor polarizer. As an excitation source, we used a CW Ti:Sapphire laser tuned to $\sim 0.93 \mu \mathrm{m}$. The spectral resolution was $0.5 \mathrm{~nm}$. The luminescence decay was studied using a 1/4 m monochromator (Oriel 77200) and an InGaAs detector. The luminescence was excited by the output of a ns optical parametric oscillator (Horizon, Continuum) tuned to $\sim 0.96 \mu \mathrm{m}$. The luminescence decay curve was fitted with a single-exponential law, $I_{\mathrm{lum}}(t)=I_{0} \exp \left(-t / \tau_{\mathrm{lum}}\right)$.

For low-temperature (LT, $12 \mathrm{~K}$ ) absorption and luminescence studies, the sample was mounted on an APD DE-202 closed-cycle cryo-cooler equipped with an APD HC 2 Helium vacuum cryo-compressor and a Laceshore 330 temperature controller. A silver paint was used for better thermal contact between the sample and the cryo-cooler. The LT absorption spectrum was measured using a $20 \mathrm{~W}$ halogen lamp with a spectrally-calibrated emission and the OSA. The LT luminescence spectrum was measured using the same OSA. The spectra resolution was $0.2 \mathrm{~nm}$.

\section{Results and discussion}

\subsection{Surface morphology}

The morphology of the top surface of the as-grown $\mathrm{Yb}: \mathrm{LiYF}_{4}$ film was first studied using a confocal optical microscope in the reflection-mode, Fig. 4. This study revealed the presence of two contributions to the surface topography. First, these are "hills" with a transverse size of few tens of $\mu \mathrm{m}$ and a height of few $\mu \mathrm{m}$ separated by "valleys" both belonging to the Yb:LiYF4 film. On top of the "hills", dendritic polycrystalline crystalline structures due to the solvent residuals $(\mathrm{LiF})$ can be observed while the film "valleys" are clean from the solvent. No surface cracks are observed in the $\mathrm{Yb}: \mathrm{LiYF}_{4}$ film. Such a morphology is typical for LPE-grown fluoride thin-films [33,35]. The bumpy surface of the layer is attributed to two main reasons. First, upon extraction from the solution, a thin liquid film (about few $\mu \mathrm{m}$ ) cannot be completely removed. Upon cooling, this film crystallizes leading to an additional increase of the layer thickness and a precipitation of the excess of $\mathrm{LiF}$ at the surface forming the dendritic structures. Second, a tendency to follow such a morphology can be assigned to higher viscosity of the flux at lower growth temperatures determined by the selected composition of the solution. Moving the bath 
composition closer to the peritectic point is expected to reduce the flux viscosity potentially improving the surface smoothness of the epitaxial layer.

It is known that the excess of the melt can be removed from the layer surface by fast spinning in the horizontal dipping geometry of LPE. It was used for the fabrication of fluoride ( $\mathrm{Yb}: \mathrm{CaF}_{2}$ ) epitaxial layers [38]. However, vertical dipping keeping a small part of the substrate clean is useful for further polishing of the epitaxy when this part is used as a plane reference. It also prevents the Pt holder from being covered by crystallized solvent (otherwise, it may be difficult to remove the epitaxy without fracturing it).

The surface roughness of the film was further examined, Fig. 5. This plot clearly reveals the presence of "hills" and "valleys", as well as sharp solvent residuals. The root mean square (r.m.s.) surface roughness is about $0.7 \mu \mathrm{m}$. For comparison, the thickness of the films used in this study lies in the range of $40-100 \mu \mathrm{m}$. Note that the surface roughness of the laser-gradepolished $\mathrm{LiYF}_{4}$ substrates is in the nanometer range.

The substrate / layer interface was further studied by observing the polished end-facet of the epitaxy using a confocal laser microscope in transmission mode (such mode allowed us to avoid the effect of the surface imperfections), Fig. 6. A clean and straight interface is observed. No cracks in the film propagating along its growth direction are visible, see Fig. 6(a). The light intensity for the layer is slightly different owing to the refractive index variation due to the $\mathrm{Yb}^{3+}$ doping. For the substrate / layer interface observed with crossed polarizers (P \| [001], A \| [100]), Fig. 6(b), only a weak stress field in the substrate is visible, which means a weak lattice mismatch for the films.

The "hilly" surface morphology of the as-grown epitaxial films does not present a serious limitation for their applications. Typically, the as-grown epitaxies are subjected to top surface polishing to ensure a uniform layer thickness, as well as to control the latter in a precise way. The final (post-polishing) thickness of the layer, as well as the refractive index contrast with respect to the substrate determine the mode guiding properties of the epitaxy (e.g., singletransverse-mode operation). Moreover, the top polishing eliminates the unwanted surface roughness and reduces the propagation losses in the layer. Another approach to produce a relatively smooth surface of the $\mathrm{RE}^{3+}$-doped (active) layer is its overgrowth by an undoped cladding layer: during the thermal equilibrium step before the overgrowth, the rough layer surface will be liquified leading to a smooth layer / cladding interface [19]. In this case, the surface state of the cladding is not very critical. For waveguide applications, two opposite side facets of the epitaxy should be polished as well.

The processing of epitaxies intended for the use in thin-disk elements is similar, i.e., it involves laser-grade polishing of the layer surface and the opposite substrate face [32]. Later on, both surfaces are subjected to dielectric coatings and the substrate is soldered to a heat sink. Note that for thin-disk laser applications, the epitaxies do not need to exhibit a refractive index contrast. The fabrication of thin-disk elements based on the LPE technology can be referred as a "bottom-up" approach. The more widespread one (a "top-down" approach) is the fabrication of thin crystal plates from bulk crystals by mechanical processing. It enables fabrication of plates with a thickness ranging between few tens and few hundreds of $\mu \mathrm{m}$ (depending on the mechanical properties of the material). The "top-down" approach is simpler from the 
technological point of view; however, such thin crystal plates suffer from internal stresses and surface bulging both affecting their laser performance. However, LPE-based thin-disk laser elements have not been commercialized so far.

The fabrication of planar waveguides by direct optical bonding of thinned crystal plates prepared from bulk crystals is also known [39]. Mackenzie et al. developed single- and doublecladding planar waveguide structures produced by direct bonding of undoped and $\mathrm{RE}^{3+}$-doped $\mathrm{Y}_{3} \mathrm{Al}_{5} \mathrm{O}_{12}$ and sapphire $\left(\alpha-\mathrm{Al}_{2} \mathrm{O}_{3}\right)$ crystal plates [40]. Such systems appear promising for power scaling at the expense of tolerated spatial beam quality. However, a direct application of this approach to fluorides will face a problem of lower hardness of the latter (as compared to oxides mentioned above). Handling with $\mathrm{LiYF}_{4}$ crystal plates with a thickness below $100 \mu \mathrm{m}$ is very complicated and from this point of view, LPE is more reliable and reproducible.

\subsection{Structural study}

The phase purity and the structure of the grown films were confirmed by X-ray diffraction (XRD), Fig. 7(a). In the measured XRD pattern of the film, only the reflections assigned to the tetragonal $\mathrm{LiYF}_{4}$ phase (cf. Fig. 7(b) showing the diffraction peaks according to the Inorganic Crystal Structure Database (ICSD) card No. 81-2254 [41]) are observed. The 20 at.\% Yb:LiYF4 film has a tetragonal structure (sp. gr. $\mathrm{C}_{4 \mathrm{~h}}^{6}-I_{1} / a$, No. 88 , centrosymmetric point group $4 / \mathrm{m}$ ). The films are isostructural to undoped $\mathrm{LiYF}_{4}$ which presents a scheelite $\left(\mathrm{CaWO}_{4}\right)$ type structure. The orientation of the film well follows that of the bulk undoped $\mathrm{LiYF}_{4}$ substrate, namely, along the [001] axis. Indeed, in the XRD pattern, there are only two intense reflections both corresponding to the (00l) Miller's indices, namely (004) at $2 \theta \approx 33.4^{\circ}$ and (008) at $2 \theta \approx$ $70.2^{\circ}$. By plotting the measured XRD pattern in a semi-log scale, we make it possible to observe weak parasitic reflections coming from slight mosaicity of the film among which, the peak at $2 \theta \approx 38.3^{\circ}$ can be unambiguously assigned as (202). However, their intensity is by 3 orders of magnitude weaker than that for the $(00 l)$ reflections.

Prior to further discussion, we describe shortly the structure of $\mathrm{Yb}: \mathrm{LiYF}_{4}$. For undoped $\mathrm{LiYF}_{4}$, the lattice constants are $a=5.164(1) \AA$ and $c=10.741(2) \AA$ (the number of the formula units in the unit-cell: $Z=4$ ), so that the volume of the unit-cell $V$ is $286.5(1) \AA^{3}$ and the theoretical density $\rho_{\text {calc }}=3.99 \mathrm{~g} / \mathrm{cm}^{3}[2]$. The $\mathrm{Li}^{+}$ion has four and the $\mathrm{Y}^{3+}$ ion has eight nearestneighbor $\mathrm{F}^{-}$ions. The two $\mathrm{Y}-\mathrm{F}$ distances are $2.244 \AA$ and $2.297 \AA$ [2]. The symmetry of the $\mathrm{Y}^{3+}$ site in the slightly distorted dodecahedron $\left[\mathrm{YF}_{8}\right]$ is $\mathrm{S}_{4}$ (a slight distortion of $\mathrm{D}_{2 \mathrm{~d}}$ for scheelite crystals) $[2,41]$. The $\left[\mathrm{LiF}_{4}\right]$ tetrahedra are corner-sharing with the edge-sharing [YF8] dodecahedrons.

When doped with $\mathrm{Yb}^{3+}$ ions, the latter are expected to replace the $\mathrm{Y}^{3+}$ ones in the $\mathrm{S}_{4}$ symmetry sites. This process is favored by the closeness of ionic radii of these cations $\left(R_{\mathrm{Yb}}=\right.$ $1.12 \AA$ and $R \mathrm{Y}=1.16 \AA$ for the VIII-fold fluorine coordination [42]). Note that the isostructural stoichiometric compound, $\mathrm{LiYbF}_{4}$, exists [43]. Its lattice constants are $a=5.133 \AA$ and $c=$ $10.587 \AA[43]$.

A close look on the (008) reflection, Fig. 7(c), reveals a split peak structure, with the narrower component at smaller $2 \theta$ angles (related to the substrate) and the broader one at higher 
$2 \theta$ (corresponding to the film). This reflects the decrease of the lattice constants of the film due to the difference in ionic radii of $\mathrm{Y}^{3+}$ and $\mathrm{Yb}^{3+}$.

To determine the lattice constants of the film, we used the following equation for tetragonal crystals:

$$
\sin ^{2} \theta=\frac{\lambda^{2}}{4}\left(\frac{h^{2}+k^{2}}{a^{2}}+\frac{l^{2}}{c^{2}}\right)
$$

where $\theta$ is the diffraction angle, $(h k l)$ are the Miller's indices of the reflection, and $\lambda=0.15406$ $\mathrm{nm}$ is the wavelength of X-rays. We analyzed the (134), (202), (004) and (008) reflections which were unambiguously assigned. The resulted values are $a=5.157 \AA$ and $c=10.714 \AA$. They are smaller than those for the undoped crystal, as expected. The lattice mismatch $\Delta a / a_{\text {subst }}$ $=-0.14 \%$ and $\Delta c / c_{\text {subst }}=-0.25 \%$. The compositions $\mathrm{LiYF}_{4}-\mathrm{LiYbF}_{4}$ form an isostructural series of solid solutions $\mathrm{LiY}_{1-x} \mathrm{Yb}_{x} \mathrm{~F}_{4}$, so that a linear evolution of the lattice constants is expected yielding to the following calculated values: $a_{\text {calc }}=5.158 \AA$ and $c_{\text {calc }}=10.710 \AA$, which are in good agreement with the experimental observations.

The reciprocal space mapping (RSM) of the (103) node for the Yb:LiYF 4 layer is shown in Fig. 8(a) and it leads to the corresponding rocking curve, Fig. 8(b). The (103) direction is not perpendicular to the surface of the substrate. By this way, it takes into account the strain induced by the substrate on the lattice parameter $a$ in the plane of the epitaxial layer. The full width at half maximum (FWHM) of the rocking curve is $0.113^{\circ}$, which reflects very low mosaicity of the crystalline film. In other words, there is a weak local disorientation of crystalline planes regarding the normal to the surface.

A typical EDX spectrum of the raw surface of the $\mathrm{Yb}: \mathrm{LiYF}_{4}$ film is shown in Fig. 9. The EDX clearly confirms the presence of $\mathrm{Yb}^{3+}$ ions in the film, together with the host-forming elements (Y, F). Note that light Li atoms cannot be detected by EDX. A weak signal from $\mathrm{O}$ originate from the post-growth hydroxyl and oxygen absorption on the residual solvent, while the Si traces can be explained either by possible weak contamination coming from the LPE silica tube constituting the growth chamber or by a Si pollution of the SEM chamber which is also used for analyzing Si wafers. The traces of $\mathrm{C}$ are referred to organic contamination of the sample, especially by the use of acetone for cleaning the sample.

The actual concentration of $\mathrm{Yb}^{3+}$ ions in the layer with respect to $\mathrm{Y}^{3+}$ was determined by EDX to be $19.6 \pm 1$ at. $\%\left(N_{\mathrm{Yb}}=27.0 \times 10^{20} \mathrm{~cm}^{-3}\right)$, corresponding to a segregation coefficient $K_{\mathrm{Yb}}$ $=N_{\text {layer }} / N_{\text {solution }}=0.98 \pm 0.05$, in agreement with our previous studies [22,23]. Close to unity value of $K_{\mathrm{Yb}}$ is determined by the small difference of ionic radii of $\mathrm{Y}^{3+}$ and $\mathrm{Yb}^{3+}$ cations. The layers exhibited a relatively uniform distribution of $\mathrm{Yb}^{3+}$ ions, with a variation of $\sim 2$ at.\% along the dipping (vertical) direction.

\subsection{Raman spectra}

The polarized Raman spectra were measured using a polished end-facet of the epitaxy in the $\boldsymbol{a}(i j) \boldsymbol{a}$ configuration (where both $i, j=\pi$ or $\sigma$ ), according to the Porto's notations [44]. The studies were performed for both the bulk $\mathrm{LiYF}_{4}$ substrate and the Yb:LiYF 4 thin-film. The results are shown in Fig. 10. 
$\mathrm{LiYF}_{4}$ crystallizes in the scheelite structure. The scheelite primitive cell containing two $\mathrm{LiYF}_{4}$ formula units has 36 degrees of freedom. At the center of the Brillouin zone $\Gamma(\boldsymbol{k}=0)$, these vibrational modes are distributed over the irreducible representations of $\mathrm{C}_{4 \mathrm{~h}}$ as follows: $3 A_{g}+5 B_{g}+5 E_{g}+5 A_{u}+3 B_{u}+5 E_{u}[6]$. One $A_{u}$ and one $E_{u}$ modes correspond to rigid translations of the whole crystal, and other $\mathrm{A}_{\mathrm{u}}$ and $\mathrm{E}_{\mathrm{u}}$ modes are IR-active. The gerade $(\mathrm{g})$ modes $\left(5 \mathrm{~B}_{\mathrm{g}}+5 \mathrm{E}_{\mathrm{g}}\right)$ are Raman-active and the remaining modes $\left(\mathrm{B}_{\mathrm{u}}\right)$ are silent.

In the Raman spectra of the substrate, Fig. 10(a), the most intense mode at $262 \mathrm{~cm}^{-1}$ is assigned as $\mathrm{Ag}_{\mathrm{g}}$. The highest energy vibrations are observed at $424\left(\mathrm{~B}_{\mathrm{g}}\right)$ and $443\left(\mathrm{Eg}_{\mathrm{g}}\right) \mathrm{cm}^{-1}$. These two are related to the Li motions. In $\mathrm{LiYF}_{4}$, the internal binding of the $\left[\mathrm{LiF}_{4}\right]^{-}$tetrahedra does not differ too much from other ionic forces in the crystal, so it is difficult to assign the internal and external vibrations $[6,45]$.

For the layer, the polarized Raman properties are well preserved, Fig. 10(b). There are only minor shifts in the peak positions of the bands (within $1 \mathrm{~cm}^{-1}$ ). This is in agreement with the Raman observations for stoichiometric $\mathrm{LiYbF}_{4}[43,45]$. The differences are revealed by examining the intense bands at 262 and $424 \mathrm{~cm}^{-1}$. For both bands, the peak Raman intensity for the film decreases and the bands are broadened. Indeed, the FWHM of the $424 \mathrm{~cm}^{-1}$ band increases from $11.3 \mathrm{~cm}^{-1}$ (substrate) to $13.0 \mathrm{~cm}^{-1}$ (film). Thus, we conclude that the anisotropic crystal structure of $\mathrm{LiYF}_{4}$ is well preserved for the film, however, a certain reduction of its crystallinity with respect to the substrate is expected.

\subsection{Optical spectroscopy}

Tetragonal $\mathrm{LiYF}_{4}$ crystals are optically uniaxial (the optical axis is parallel to the crystallographic $\boldsymbol{c}$-axis) [5]. Thus, there exist two principal light polarizations, denoted as $\pi$ (E $\| \boldsymbol{c})$ and $\sigma(\boldsymbol{E} \perp \boldsymbol{c})$ with the corresponding refractive indices $n_{\mathrm{e}}$ and $n_{\mathrm{o}}$. As $n_{\mathrm{e}}>n_{\mathrm{o}}$, this crystal is positive uniaxial.

For comparison, we studied a 10 at. $\%$ Yb:LiYF 4 bulk crystal.

The stimulated-emission (SE) cross-sections, $\sigma \mathrm{SE}$, were determined from the measured RT luminescence spectra calibrated for the spectral response of the set-up $W_{i}^{\prime}(\lambda)$ using the Füchtbauer-Ladenburg (F-L) equation [46]:

$$
\sigma_{\mathrm{SE}}^{i}(\lambda)=\frac{\lambda^{5}}{8 \pi<n>^{2} \tau_{\mathrm{rad}} c} \frac{W_{i}^{\prime}(\lambda)}{1 / 3 \sum_{j=2 \sigma, \pi} \int_{, \pi} \lambda W_{j}^{\prime}(\lambda) \mathrm{d} \lambda},
$$

where, $\lambda$ is the light wavelength, $\langle n\rangle$ is the mean refractive index at the emission wavelength $\left\langle\lambda_{\text {lum }}>, c\right.$ is the speed of light, $\tau_{\text {rad }}$ is the radiative lifetime of the emitting state ${ }^{2} \mathrm{~F}_{5 / 2}$ and $i=\pi$ or $\sigma$ is the light polarization. The polarization-averaging is performed as $1 / 3(2 \sigma+\pi)$.

The results are shown in Fig. 11(a). For the LPE-grown film, the maximum $\sigma_{\mathrm{SE}}$ is $0.88 \times 10^{-20} \mathrm{~cm}^{2}$ at $993.9 \mathrm{~nm}$ in $\pi$-polarization. Another intense emission peak is observed at $1018.8 \mathrm{~nm}$. These two peaks are assigned to the $0^{\prime} \rightarrow 1,2$ and $0^{\prime} \rightarrow 3$ transitions, respectively (here, $s=0 \ldots 3$ and $p^{\prime}=00^{\prime} . .22^{\prime}$ indices number the Stark sub-levels of the ground-state and the excited-state, respectively, as each ${ }^{2 \mathrm{~S}+1} \mathrm{~L}_{J}$ multiplet is split into a total of $2 J+1$ sub-levels [47]). The total emission bandwidth (FWHM) $\Delta \lambda_{\text {lum }}$ is $41.2 \mathrm{~nm}$ (if analyzing the peaks separately, it 
is $\sim 18 \mathrm{~nm}$ for the most intense one). For $\sigma$-polarization, the $\mathrm{SE}$ cross-sections are lower, namely $\sigma \mathrm{SE}=0.42 \times 10^{-20} \mathrm{~cm}^{2}$ at $1018.1 \mathrm{~nm}$.

The SE cross-sections for the film slightly differ from those for the highly-doped bulk crystal, Fig. 11(a). In particular, the emission band for the film is broadened, as expressed by

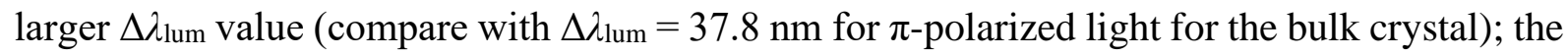
peak $\sigma$ SE value for the film is also slightly reduced. The broadening of the emission band is confirmed by calculation of the polarization-averaged integrated $\sigma$ SE value which is almost the same for both the bulk crystal and the layer. The reduction in intensity and broadening of the emission spectra for the films is in line with the results of Raman spectroscopy.

Previously for heavily doped (30 at.\%) Yb:LiYF4 single-crystals, Vannini et al. reported $\sigma \mathrm{SE}=0.83(\pi)$ and $0.34(\sigma)\left[10^{-20} \mathrm{~cm}^{2}\right]$ at $\sim 1018 \mathrm{~nm}$ as calculated by the F-L method [8] which agrees with our observations.

The RT absorption spectrum for the epitaxy was measured for light propagating orthogonal to the polished top-surface (i.e., along the $\boldsymbol{c}$-axis). Thus, only the $\sigma$-polarization was available. The absorption cross-sections were calculated from the measured absorption coefficient, $\sigma_{\mathrm{abs}}=\alpha_{\mathrm{abs}} / N_{\mathrm{Yb}}$, where $N_{\mathrm{Yb}}=2.75 \times 10^{21} \mathrm{~cm}^{-3}$ is the $\mathrm{Yb}^{3+}$ ion density. For another polarization $(\pi)$, the absorption cross-sections were calculated using the corresponding $\sigma \mathrm{SE}$ spectrum with the reciprocity method (RM) [48]:

$$
\begin{aligned}
& \sigma_{\mathrm{SE}}(\lambda)=\sigma_{\mathrm{abs}}(\lambda) \frac{Z_{1}}{Z_{2}} \exp \left(-\frac{h c / \lambda-E_{\mathrm{ZPL}}}{k T}\right), \\
& Z_{m}=\sum_{k} g_{k}^{m} \exp \left(-E_{k}^{m} / k T\right) .
\end{aligned}
$$

Here, $h$ is the Planck constant, $h c / \lambda$ is the photon energy (in $\mathrm{cm}^{-1}$ ), $k$ is the Boltzmann constant, $T$ is the crystal temperature (RT), EzPL is the energy difference between the lowest lying Stark sub-levels of the two multiplets (the so-called zero-phonon line (ZPL), $\left.0 \rightarrow 0^{\prime}\right), Z_{\mathrm{m}}$ are the partition functions of the lower $(m=1)$ and upper $(m=2) \mathrm{Yb}^{3+}$ multiplets, $g^{\mathrm{m}_{\mathrm{k}}}$ is the degeneracy of the sub-level with the number $k$ and the energy $E^{\mathrm{m}_{\mathrm{k}}}$ measured from the lowest sub-level of each multiplet. Such a calculation could suffer from reabsorption losses affecting the measured luminescence spectra. However, this effect is greatly reduced in the studied films with a thickness of few tens of $\mu \mathrm{m}$.

The $\sigma_{\mathrm{abs}}$ spectra are shown in Fig. 11(b). For the Yb:LiYF4 layers, the maximum $\sigma_{\mathrm{abs}}=$ $0.67 \times 10^{-20} \mathrm{~cm}^{2}$ at $959.7 \mathrm{~nm}$ in $\pi$-polarization and the FWHM of the absorption peak is $19.3 \mathrm{~nm}$. For $\sigma$-polarization, the absorption cross-section at the same wavelength is lower $\left(\sigma_{\mathrm{abs}}=0.48 \times 10^{-}\right.$ ${ }^{20} \mathrm{~cm}^{2}$ ). This absorption line is due to the $0 \rightarrow 1$ ' transition. As compared to those for the singlecrystal, the absorption spectra experience a broadening which is especially evident for $\pi$ polarization.

The crystal-field splitting for $\mathrm{Yb}^{3+}$ multiplets in $\mathrm{Yb}: \mathrm{LiYF}_{4}$ epitaxial films was determined from LT absorption and emission spectra, Fig. 12. The spectra were interpreted accounting for the Raman spectra in order to exclude the vibronic sidebands (marked in Fig. 12 by " $h v$ "). The assignment of electronic transitions (between the Stark sub-levels) is according to $[47,49]$. The following set of Stark sub-levels was obtained: ${ }^{2} \mathrm{~F}_{7 / 2}=(0,216,245,482) \mathrm{cm}^{-1}$ and ${ }^{2} \mathrm{~F}_{5 / 2}=$ $(10295,10420,10554) \mathrm{cm}^{-1}$, cf. Fig. 13, yielding the partition functions $Z_{1}=1.820$ and $Z_{2}=$ 
1.739 and the ratio $\mathrm{Z}_{1} / \mathrm{Z}_{2}=0.955$ (at room temperature). The determined Stark splitting is similar to that reported previously for bulk low-doped 0.5 at.\% Yb:LiYF 4 crystal, namely ${ }^{2} \mathrm{~F}_{7 / 2}$ $=(0,218,248,485) \mathrm{cm}^{-1}$ and ${ }^{2} \mathrm{~F}_{5 / 2}=(10293,10416,10554) \mathrm{cm}^{-1}$ [47].

For $\mathrm{Yb}^{3+}$ ions, the luminescence at $\sim 1 \mu \mathrm{m}$ spectrally overlaps with the absorption due to the ${ }^{2} \mathrm{~F}_{7 / 2} \rightarrow{ }^{2} \mathrm{~F}_{5 / 2}$ transition. Thus, with increasing the $\mathrm{Yb}^{3+}$ doping level, the luminescence lifetime $\tau_{\text {lum }}$ measured for bulk samples can be elongated due to reabsorption (also called the radiation trapping effect). To avoid it, several approaches were proposed, such as the pinhole method [50] and the powder suspension method [51]. The first one is non-destructive and thus it was selected in the present work.

Other possible effects which may influence $\tau_{\text {lum }}$ are the concentration-quenching and the energy-migration to impurities both leading to the shortening of the lifetime. Note that for $\mathrm{Yb}^{3+}$ ions in $\mathrm{LiYF}_{4}$, the non-radiative relaxation from the emitting state $\left({ }^{2} \mathrm{~F}_{5 / 2}\right)$ is negligible.

The RT luminescence decay curve for the 20 at.\% Yb:LiYF4 epitaxy is shown in Fig. 14(a), as measured using the smallest pinhole diameter $d$. It is clearly single-exponential in agreement with a single site for $\mathrm{Yb}^{3+}$ ions (symmetry: $\mathrm{S}_{4}, \mathrm{C} . \mathrm{N} .=\mathrm{VIII}$ ). The extrapolation of the linear fit of the dependence of $\tau_{\text {lum }}$ on $d$, Fig. 14(b), to the limit of $d \rightarrow 0$ gives an estimation for the radiation-trapping free lifetime $\tau_{0}=2.00 \pm 0.05 \mathrm{~ms}$.

For comparison, we also studied two bulk $\mathrm{Yb}: \mathrm{LiYF}_{4}$ crystals doped with 2 at.\% and 10 at.\% Yb. The corresponding decay curves are shown in Fig. 14(a). For the crystal with 2 at.\% $\mathrm{Yb}, \tau_{0}=2.26 \mathrm{~ms}$. Its only slightly decreased for the crystal with 10 at.\% Yb (2.24 ms). Thus, the concentration-quenching owing to the energy migration for this range of doping concentrations is relatively week. From this considerations, one can assume that $\tau_{0} \approx \tau_{\text {rad. }}$ The slightly lower $\tau_{0}$ for the film than that for the single-crystal may originate from the varied crystal-field both due to the form of the material (thin crystalline film) and high $\mathrm{Yb}^{3+}$ doping.

Previously, De Loach et al. determined the luminescence lifetime for $\mathrm{Yb}: \mathrm{LiYF}_{4}$ crystals with a low doping concentration (the so-called intrinsic one) as $\tau_{\text {lum }, 0}=2.16 \mathrm{~ms}$ [52]; the authors also estimated the radiative lifetime by means of the RM as $\tau_{\mathrm{rad}}=2.27 \mathrm{~ms}$. Yasukevich et al. evaluated $\tau_{\text {lum,o }}$ for the isostructural $\mathrm{Yb}: \mathrm{LiLuF}_{4}$ crystal by the powder suspension method to be $1.94 \mathrm{~ms}$ [53]. Our work agrees well with these results.

\section{Conclusions}

Liquid Phase Epitaxy is a suitable method for the growth of highly-doped (20 at.\% Yb, in the present work) $\mathrm{Yb}^{3+}: \mathrm{LiYF}_{4}$ single-crystalline thin-films on undoped $\mathrm{LiYF}_{4}$ substrates. In the present work, the maximum film thickness of $215 \mu \mathrm{m}$ was reached; it can be varied by changing the dipping duration and the growth temperature. The grown films show a proper orientation, high crystallinity and low mosaicity, a uniform thickness over the substrate with the lack of cracks and well-preserved anisotropic emission properties of $\mathrm{Yb}^{3+}$ ions. A slight broadening of the emission spectrum of the $\mathrm{Yb}^{3+}: \mathrm{LiYF}_{4}$ thin films (more evident for the $\pi$ polarization) is detected as compared to the corresponding single-crystals which may be favorable for laser applications, especially for mode-locked lasers. A weak concentrationquenching is observed as confirmed by the radiation trapping free upper laser level lifetime, $\sim 2.0 \mathrm{~ms}$, indicating weak unwanted energy-transfer to impurities. 
The developed epitaxies are attractive for thin-disk laser applications. For a $100 \mu \mathrm{m}$-thick film, the estimated small-signal single-bounce (double-pass) pump absorption at $960 \mathrm{~nm}$ is $\sim 23 \%$. This parameter can be further increased by growing films with even higher doping levels (30-50 at.\% Yb); however, this may be accompanied by stronger effect of energy-migration on the upper laser level lifetime. Still, the lattice mismatch for such $\mathrm{Yb}^{3+}$ doping levels is expected to be low. Another alternative is the use of (100) oriented $\mathrm{LiYF}_{4}$ substrates. This will allow one to access another light polarization $(\pi)$ corresponding to higher transition cross-sections both in absorption and emission. However, a possible challenge here is the anisotropy of the thermal conductivity and thermal expansion in the film plane.

\section{Acknowledgements}

This work was supported by French Agence Nationale de la Recherche (ANR) through the projects LabEx EMC3 (ANR-10-LABX-09-01), SPLENDID2 (ANR-19-CE08-0028), and the European project "NOVAMAT" co-funded by the European Community funds FEDER and the Normandie region.

\section{References}

1. P. Loiko, J. M. Serres, X. Mateos, S. Tacchini, M. Tonelli, S. Veronesi, D. Parisi, A. Di Lieto, K. Yumashev, U. Griebner, V. Petrov, Comparative spectroscopic and thermo-optic study of $\mathrm{Tm}: \mathrm{LiLnF}_{4}(\mathrm{Ln}=\mathrm{Y}, \mathrm{Gd}$, and Lu) crystals for highly-efficient microchip lasers at $\sim 2 \mu \mathrm{m}$, Opt. Mater. Express 7 (2017) 844-854.

2. E. Garcia, R.R. Ryan, Structure of the laser host material $\mathrm{LiYF}_{4}$, Acta Cryst. C49 (1993) 2053 2054.

3. R.L. Aggarwal, D.J. Ripin, J.R. Ochoa, T.Y. Fan, Measurement of thermo-optic properties of $\mathrm{Y}_{3} \mathrm{Al}_{5} \mathrm{O}_{12}, \mathrm{Lu}_{3} \mathrm{Al}_{5} \mathrm{O}_{12}, \mathrm{YAIO}_{3}, \mathrm{LiYF}_{4}, \mathrm{LiLuF}_{4}, \mathrm{BaY}_{2} \mathrm{~F}_{8}, \mathrm{KGd}\left(\mathrm{WO}_{4}\right)_{2}$, and $\mathrm{KY}\left(\mathrm{WO}_{4}\right)_{2}$ laser crystals in the 80-300 K temperature range, J. Appl. Phys. 98 (2005) 103514.

4. P.J. Hardman, W.A. Clarkson, G.J. Friel, M. Pollnau, D.C. Hanna, Energy-transfer upconversion and thermal lensing in high-power end-pumped Nd:YLF laser crystals, IEEE J. Quantum Electron. 35 (1999) 647-655.

5. N.P. Barnes, D.J. Gettemy, Temperature variation of the refractive indices of yttrium lithium fluoride, J. Opt. Soc. Am. 70 (1980) 1244-1247.

6. S.A. Miller, H.E. Rast, H.H. Caspers, Lattice vibrations of LiYF, J. Chem. Phys. 52 (1970) 4172-4175.

7. B.M. Walsh, N.P. Barnes, M. Petros, J. Yu, U.N. Singh, Spectroscopy and modeling of solid state lanthanide lasers: Application to trivalent $\mathrm{Tm}^{3+}$ and $\mathrm{Ho}^{3+}$ in $\mathrm{YLiF}_{4}$ and $\mathrm{LuLiF}_{4}$, J. Appl. Phys. 95 (2004) 3255-3271.

8. M. Vannini, G. Toci, D. Alderighi, D. Parisi, F. Cornacchia, M. Tonelli, High efficiency room temperature laser emission in heavily doped Yb:YLF, Opt. Express 15 (2007) 7994-8002.

9. B. Cockayne,J.G. Plant, R.A. Clay, The czochralski growth and laser characteristics of $\mathrm{Li}(\mathrm{Y}, \mathrm{Er}, \mathrm{Tm}, \mathrm{Ho}) \mathrm{F}_{4}$ and $\mathrm{Li}(\mathrm{Lu}, \mathrm{Er}, \mathrm{Tm}, \mathrm{Ho}) \mathrm{F}_{4}$ scheelite single crystals, J. Cryst. Growth 54 (1981) 407-413.

10. W.A. Clarkson, P.J. Hardman, D.C. Hanna, High-power diode-bar end-pumped Nd:YLF laser at $1.053 \mu \mathrm{m}$, Opt. Lett. 23 (1998) 1363-1365. 
11. N. Coluccelli, G. Galzerano, L. Bonelli, A. Toncelli, A. Di Lieto, M. Tonelli, P. Laporta, Room-temperature diode-pumped $\mathrm{Yb}^{3+}$-doped $\mathrm{LiYF}_{4}$ and $\mathrm{KYF}_{4}$ lasers, Appl. Phys. B 92 (2008) 519-523.

12. J. Kawanaka, H. Nishioka, N. Inoue, K. Ueda, Tunable continuous-wave Yb:YLF laser operation with a diode-pumped chirped-pulse amplification system, Appl. Opt. 40 (2001) 35423546.

13. A.S. Yasukevich, V.E. Kisel, S.V. Kurilchik, S.V. Grigoriev, N.V. Kuleshov, E.Y. Gordeev, S.L. Korableva, A.K. Naumov, V.V. Semashko, Continuous wave diode pumped Yb:LLF and Yb:NYF lasers, Opt. Commun. 282 (2009) 4404-4407.

14. N. Coluccelli, G. Galzerano, L. Bonelli, A. Di Lieto, M. Tonelli, P. Laporta, Diode-pumped passively mode-locked Yb:YLF laser, Opt. Express 16 (2008) 2922-2927.

15. H. Lin, F. Pirzio, A. Volpi, G. Cittadino, A. Di Lieto, M. Tonelli, A. Agnesi, Crystal growth, spectroscopic characterization, and sub-100 femtosecond mode-locked operation of a Yb:LiLuF 4 laser, J. Opt. Soc. Am. B 33 (2016) 2350-2356.

16. F. Pirzio, L. Fregnani, A. Volpi, A. Di Lieto, M. Tonelli, A. Agnesi, 87 fs pulse generation in a diode-pumped semiconductor saturable absorber mirror mode-locked Yb:YLF laser, Appl. Opt. 55 (2016) 4414-4417.

17. L.E. Zapata, D.J. Ripin, T.Y. Fan, Power scaling of cryogenic Yb:LiYF 4 lasers," Opt. Lett. 35 (2010) 1854-1856.

18. D.V. Seletskiy, S.D. Melgaard, R.I. Epstein, A. Di Lieto, M. Tonelli, M. Sheik-Bahae, Local laser cooling of Yb:YLF to $110 \mathrm{~K}$, Opt. Express 19 (2011) 18229-18236.

19. P. Rogin, J. Hulliger, Liquid phase epitaxy of $\mathrm{LiYF}_{4}$, J. Cryst. Growth 179 (1997) 551-558.

20. F. Starecki, W. Bolaños, G. Brasse, A. Benayad, M. Morales, J.L. Doualan, A. Braud, R.

Moncorgé, P. Camy, Rare earth doped $\mathrm{LiYF}_{4}$ single crystalline films grown by liquid phase epitaxy for the fabrication of planar waveguide lasers, J. Cryst. Growth 401 (2014) 537-541.

21. F. Starecki, W. Bolaños, A. Braud, J.-L. Doualan, G. Brasse, A. Benayad, V. Nazabal, B. Xu, R. Moncorgé, P. Camy, Red and orange $\operatorname{Pr}^{3+}: \mathrm{LiYF}_{4}$ planar waveguide laser, Opt. Lett. 38 (2013) 455457.

22. W. Bolaños, F. Starecki, A. Braud, J.-L. Doualan, R. Moncorgé, P. Camy, 2.8 W end-pumped $\mathrm{Yb}^{3+}: \mathrm{LiYF}_{4}$ waveguide laser, Opt. Lett. 38 (2013) 5377-5380.

23. P. Loiko, R. Soulard, G. Brasse, J.-L. Doualan, B. Guichardaz, A. Braud, A. Tyazhev, A. Hideur, P. Camy, Watt-level Tm:LiYF 4 channel waveguide laser produced by diamond saw dicing, Opt. Express 26 (2018) 24653-24662.

24. P. Loiko, R. Soulard, G. Brasse, J.-L. Doulan, A. Braud, A. Tyazhev, A. Hideur, P. Camy, Tm,Ho:LiYF 4 planar waveguide laser at $2.05 \mu \mathrm{m}$, Opt. Lett. 43 (2018) 4341-4344.

25. L. Douysset-Bloch, B. Ferrand, M. Couchaud, L. Fulbert, M.F. Joubert, G. Chadeyron, B. Jacquier, Growth by liquid phase epitaxy and characterization of $\mathrm{Nd}: \mathrm{YLiF}_{4}$ layers, J. Alloys Compd. 275 (1998) 67-71.

26. C. Garapon, S. Guy, S. Skasasian, A. Bensalah, C. Champeaux, R. Brenier, Nd ${ }^{3+}$-doped $\mathrm{LiYF}_{4}$ thin films prepared by pulsed laser deposition, Appl. Phys. A 91 (2008) 493-499.

27. S. Barsanti, F. Cornacchia, A. Di Lieto, A. Toncelli, M. Tonelli, P. Bicchi, $\mathrm{Nd}^{3+}$-doped fluoride film grown on $\mathrm{LiYF}_{4}$ substrate by pulsed laser deposition, Thin Solid Films 516 (2008) 2009-2013. 28. S. Barsanti, M. Anwar-ul-Haq, P. Bicchi, Optical response and surface morphology of crystalline $\mathrm{Nd}^{3+}$-doped fluoride films grown on monocrystalline $\mathrm{LiYF}_{4}$ substrates by pulsed laser deposition, Thin Solid Films 517 (2009) 2029-2034. 
29. F. Stokker-Cheregi, A. Matei, M. Dinescu, C.E. Secu, M. Secu, Photoluminescence of Eu-doped $\mathrm{LiYF}_{4}$ thin films grown by pulsed laser deposition and matrix-assisted pulsed laser evaporation, J. Phys. D: Appl. Phys. 47 (2013) 045304-1-6.

30. S. Rivier, X. Mateos, Ò. Silvestre, V. Petrov, U. Griebner, M.C. Pujol, M. Aguiló, F. Díaz, S. Vernay, D. Rytz, Thin-disk Yb:KLu($\left(\mathrm{WO}_{4}\right)_{2}$ laser with single-pass pumping, Opt. Lett. 33 (2008) 735737.

31. S. Vatnik, I. Vedin, M. Segura, X. Mateos, M.C. Pujol, J.J. Carvajal, M. Aguiló, F. Díaz, V. Petrov, U. Griebner, Efficient thin-disk Tm-laser operation based on Tm:KLu( $\left(\mathrm{WO}_{4}\right)_{2} / \mathrm{KLu}\left(\mathrm{WO}_{4}\right)_{2}$ epitaxies, Opt. Lett. 37 (2012) 356-358.

32. X. Mateos, S. Lamrini, K. Scholle, P. Fuhrberg, S. Vatnik, P. Loiko, I. Vedin, M. Aguiló, F. Díaz, U. Griebner, V. Petrov, Holmium thin-disk laser based on Ho:KY $\left(\mathrm{WO}_{4}\right)_{2} / \mathrm{KY}\left(\mathrm{WO}_{4}\right)_{2}$ epitaxy with 60\% slope efficiency and simplified pump geometry, Opt. Lett. 42 (2017) 3490-3493.

33. R. Soulard, M. Salhi, G. Brasse, P. Loiko, J.-L. Doualan, L. Guillemot, A. Braud, A. Tyazhev, A. Hideur, P. Camy, Laser operation of highly-doped Tm:LiYF 4 epitaxies: towards thin-disk lasers, Opt. Express 27 (2019) 9287-9301.

34. R.E. Thoma, C.F. Weaver, H.A. Freidman, H. Insley, L.A. Harris, H.A. Yakel, Phase equilibria in the system $\mathrm{LiF}-\mathrm{YF}_{3}$, J. Phys .Chem. 65 (1961) 1096-1099.

35. G. Brasse, P. Loiko, C. Grygiel, P. Leprince, A. Benayad, F. Lemarie, J.L. Doualan, A. Braud, P. Camy, Liquid Phase Epitaxy growth of $\mathrm{Tm}^{3+}$-doped $\mathrm{CaF}_{2}$ thin-films based on LiF solvent, J. Alloy Compd. 803 (2019) 442-449.

36. P. Rogin, G. Huber, J. Hulliger, $\mathrm{LiYF}_{4}$ liquid phase epitaxy using an inverted slider geometry, J. Cryst. Growth 198-199 (1999) 564-567.

37. A. Boulle, DxTools: processing large data files recorded with the Bruker D8 diffractometer, J. Appl. Cryst. 50 (2017) 967-974.

38. A. Peña, P. Camy, A. Benayad, J.L. Doualan, C. Maurel, M. Olivier, V. Nazabal, R. Moncorgé, $\mathrm{Yb}: \mathrm{CaF}_{2}$ grown by liquid phase epitaxy, Opt. Mater. 33 (2011) 1616-1620.

39. D.P. Shepherd, S.J. Hettrick, C. Li, J.I. Mackenzie, R.J. Beach, S.C. Mitchell, H.E. Meissner, High-power planar dielectric waveguide lasers, J. Phys. D: Appl. Phys. 34 (2001) 2420-2432. 40. J.I. Mackenzie, S.C. Mitchell, R.J. Beach, H.E. Meissner, D.P. Shepherd, $15 \mathrm{~W}$ diode-sidepumped Tm:YAG waveguide laser at $2 \mu \mathrm{m}$, Electron. Lett. 37 (2001) 898-899.

41. E. Garcia, R.R. Ryan, Structure of the laser host material LiYF, Acta Cryst. C 49 (1993) 20532054.

42. A.A. Kaminskii, Laser crystals: their physics and properties (Springer, 2013).

43. A.A. Kaminskii, Detection of stimulated Raman scattering in the $\mathrm{LiYbF}_{4}$ crystal, Doklady Phys. 62 (2017) 120-123.

44. T.C. Damen, S.P.S. Porto, B. Tell, Raman effect in zinc oxide, Phys. Rev. 142 (1966) 570-574. 45. S. Salaün, M.T. Fornoni, A. Bulou, M. Rousseau, J.Y. Gesland, P. Simon, Lattice dynamics of fluoride scheelites: I. Raman and infrared study of $\mathrm{LiYF}_{4}$ and $\mathrm{LiLnF}_{4}(\mathrm{Ln}=\mathrm{Ho}, \mathrm{Er}, \mathrm{Tm}$ and $\mathrm{Yb}), \mathrm{J}$. Phys.: Cond. Matter 9 (1997) 6941-6956.

46. B. Aull, H. Jenssen, Vibronic interactions in Nd:YAG resulting in nonreciprocity of absorption and stimulated emission cross sections, IEEE J. Quantum Electron. 18 (1982) 925-930.

47. A. Bensalah, Y. Guyot, M. Ito, A. Brenier, H. Sato, T. Fukuda, G. Boulon, Growth of $\mathrm{Yb}^{3+}$-doped $\mathrm{YLiF}_{4}$ laser crystal by the Czochralski method, Attempt of $\mathrm{Yb}^{3+}$ energy level assignment and estimation of the laser potentiality, Opt. Mater. 26 (2004) 375-383. 
48. S.A. Payne, L.L. Chase, L.K. Smith, W.L. Kway, W.F. Krupke, Infrared cross-section measurements for crystals doped with $\mathrm{Er}^{3+}, \mathrm{Tm}^{3+}$ and $\mathrm{Ho}^{3+}$, IEEE J. Quantum Electron. 28 (1992) 2619-2630.

49. A. Lupei, V. Lupei, C. Presura, V.N. Enaki, A. Petraru, Electron-phonon coupling effects on $\mathrm{Yb}^{3+}$ spectra in several laser crystals, J. Phys. Cond. Matter 11 (1999) 3769-3778.

50. H. Kühn, S.T. Fredrich-Thornton, C. Kränkel, R. Peters, K. Petermann, Model for the calculation of radiation trapping and description of the pinhole method, Opt. Lett. 32 (2007) 1908-1910.

51. V.E. Kisel, A.E. Troshin, N.A. Tolstik, V.G. Shcherbitsky, N.V. Kuleshov, V.N. Matrosov, T.A. Matrosova, M.I. Kupchenko, Spectroscopy and continuous-wave diode-pumped laser action of $\mathrm{Yb}^{3+}: \mathrm{YVO}_{4}$, Opt. Lett. 29 (2004) 2491-2493.

52. L.D. DeLoach, S.A. Payne, L.L. Chase, L.K. Smith, W.L. Kway, W.F. Krupke, Evaluation of absorption and emission properties of $\mathrm{Yb}^{3+}$-doped crystals for laser applications, IEEE J.

Quantum Electron. 29 (1993) 1179-1191.

53. A.S. Yasyukevich, A.V. Mandrik, N.V. Kuleshov, E.Y. Gordeev, S.L. Korableva, A.K. Naumov, V.V. Semashko, P.A. Popov, Spectral kinetic properties of $\mathrm{Yb}^{3+}: \mathrm{Na}_{4} \mathrm{Y}_{6} \mathrm{~F}_{22}$ and $\mathrm{Yb}^{3+}: \mathrm{LiLuF}_{4}$ crystals, J. Appl. Spectr. 74 (2007) 844-850. 


\section{List of figure captions}

Figure 1. Phase diagram of the $\mathrm{LiF}-\mathrm{YF}_{3}$ binary system (after [34]), red solid line marks $\mathrm{LiYF}_{4}$ solid phase, blue dashed line indicates the composition selected for the LPE growth.

Figure 2. (a) Photograph of an as-grown undoped $\mathrm{LiYF}_{4}$ boule used for preparing the substrates for LPE. The growth direction is along the [001] axis; (b) Photograph of the $\mathrm{Yb}: \mathrm{LiYF}_{4} / \mathrm{LiYF}_{4}$ epitaxy directly after the LPE growth process. The substrate is oriented along the (001) plane.

Figure 3. A fragment of the phase diagram of the $\mathrm{LiF}-\mathrm{YF}_{3}$ binary system relevant for the LPE growth experiments, after Thoma et al. [34] and Rogin et al. [19]. Red squares - liquidus temperatures, red circles - apparent onset of crystallization (both after [19]), blue square - liquidus temperature, blue asterisk - growth temperature (both - this work). Blue dashed line - the selected bath composition.

Figure 4. Observation of the raw surface of a LPE-grown Yb:LiYF 4 film (top view) using a confocal optical microscope. Reflection mode, bright field, the objective magnification is $20 \times, \lambda=405 \mathrm{~nm}$.

Figure 5. Surface roughness plot of the raw surface of a LPE-grown $\mathrm{Yb}: \mathrm{LiYF}_{4}$ film, obtained using a confocal optical microscope. Black lines indicate the range of root mean square (r.m.s.) deviation, inset - the corresponding topography map, while line the analyzed direction. Reflection mode, $\lambda=405 \mathrm{~nm}$.

Figure 6. Confocal microscope images of the polished end-facet of the $\mathrm{Yb}: \mathrm{LiYF}_{4} /$ LiYF4 epitaxy: (a) polarized light, P \| [001], (b) a close look on the substrate / layer interface in crossed polarizers (P\| [001], A \| [100]). Transmission mode, the objective is (a) $20 \times$, N.A. $=0.75$, (b) $50 \times$, N.A. $=0.95, \lambda=405 \mathrm{~nm}$.

Figure 7. Single-crystal X-ray diffraction (XRD) study of the 20 at.\% Yb:LiYF 4 $\mathrm{LiYF}_{4}$ epitaxy: (a) single-crystal XRD pattern of the film; (b) theoretical XRD pattern of $\mathrm{LiYF}_{4}$ (ICSD card No. 81-2254); (c) a close look on the (008) reflection. Numbers indicate the Miller's indices, $(h k l)$.

Figure 8. (a) Reciprocal space mapping of the (103) node for the Yb:LiYF4 layer; (b) the rocking curve of this node.

Figure 9. Typical EDX spectrum of the 20 at.\% $\mathrm{Yb}: \mathrm{LiYF}_{4}$ film grown by the LPE method (top raw surface). 
Figure 10. Polarized Raman spectra of the undoped $\mathrm{LiYF}_{4}$ substrate and the LPEgrown 20 at.\% Yb:LiYF 4 layer in the $\boldsymbol{a}(i j) \boldsymbol{a}, i, j=\pi, \sigma$, configuration (Porto's notations), numbers indicate Raman frequencies in $\mathrm{cm}^{-1}, \mathrm{FWHM}$ - full width at half maximum, $\lambda_{\mathrm{exc}}=488 \mathrm{~nm}$.

Figure 11. (a) Stimulated-emission (SE), $\sigma_{\mathrm{SE}}$, and (b) absorption, $\sigma_{\mathrm{abs}}$, cross-section spectra for the ${ }^{2} \mathrm{~F}_{5 / 2} \leftrightarrow{ }^{2} \mathrm{~F}_{7 / 2} \mathrm{Yb}^{3+}$ transition in 20 at.\% Yb:LiYF 4 LPE-grown layer in $\pi$ and $\sigma$ polarizations; the spectra for the bulk 10 at.\% Yb:LiYF 4 crystal are given for comparison. $\sigma_{\text {SE: }}$ calculation using Eq. (2), the F-L formula.

Figure 12. Low-temperature (LT, $12 \mathrm{~K}$ ) absorption and luminescence spectra for the 20 at.\% Yb:LiYF 4 LPE-grown layer in $\sigma$ polarization, $\lambda_{\text {exc }}=933 \mathrm{~nm}$. "+" mark the electronic transitions, " $h v$ " - the vibronic sidebands. The spectral resolution is $0.2 \mathrm{~nm}$.

Figure 13. Crystal-field splitting of $\mathrm{Yb}^{3+}$ multiplets in highly-doped (20 at.\%) $\mathrm{Yb}: \mathrm{LiYF}_{4}$ epitaxial films, the arrows indicate the electronic transitions in absorption and emission at $12 \mathrm{~K}$.

Figure 14. (a) Luminescence decay curve for the 20 at.\% Yb:LiYF 4 LPE-grown film (a semi-log plot): black curve - experimental data, green line - single-exponential fit, the data for 2 at. $\% \mathrm{Yb}$ and 10 at.\% $\mathrm{Yb}: \mathrm{LiYF}_{4}$ bulk crystals are given for comparison, all the curves are measured using the smallest pinhole; (b) evaluation of the radiation trapping-free lifetime $\tau_{0}$ for the epitaxy by the pinhole method. $\lambda_{\mathrm{exc}}=960 \mathrm{~nm}, \lambda_{\mathrm{lum}}=$ $1030 \mathrm{~nm}$. 


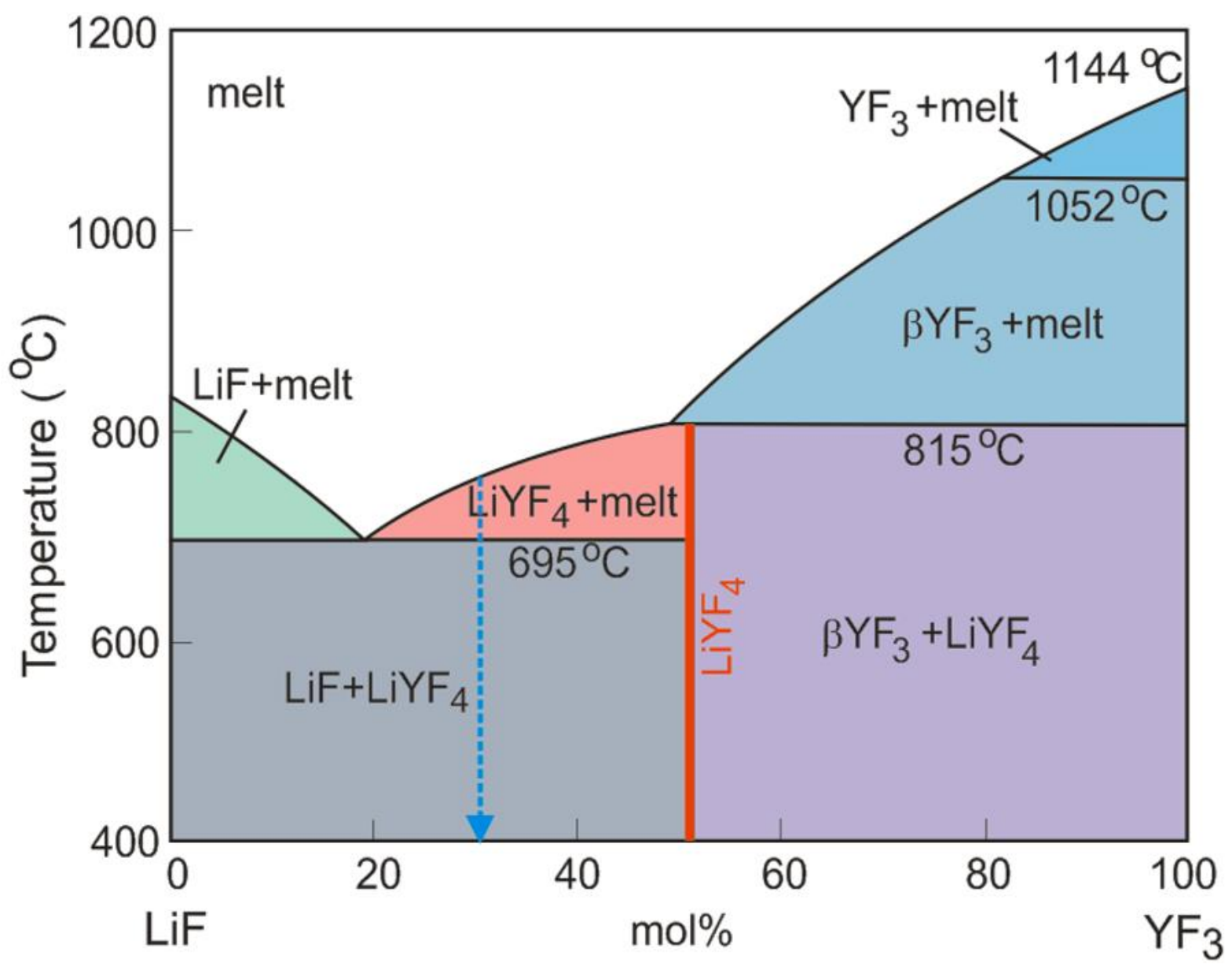


(a)

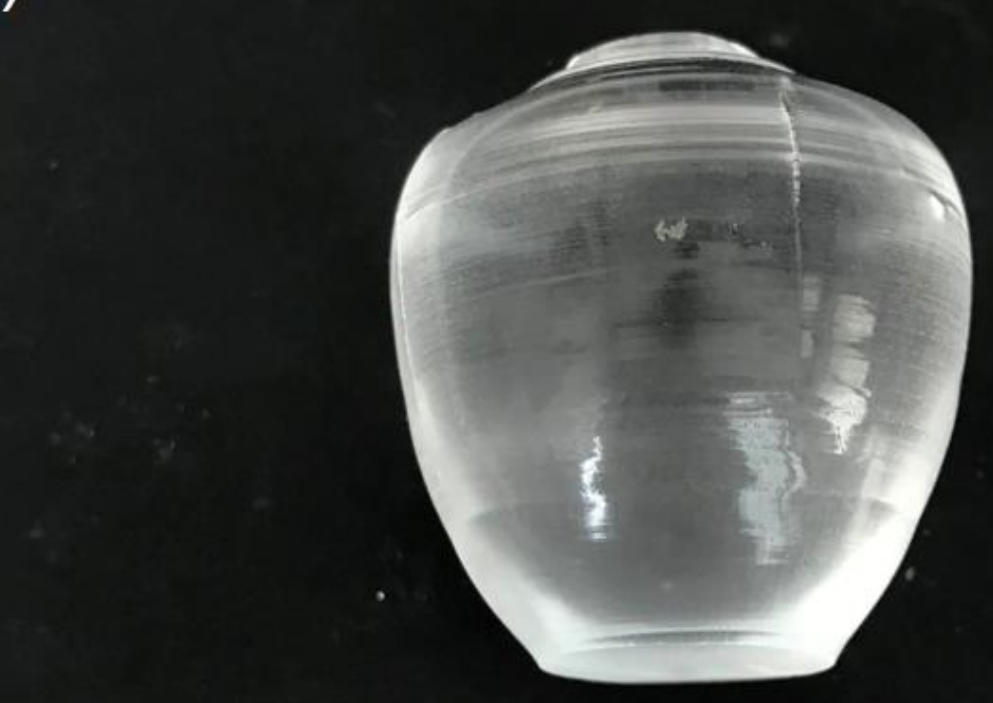

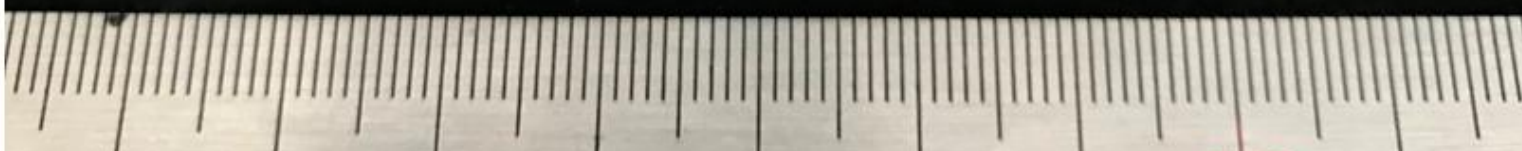
$\begin{array}{lllllllll}3 & 4 & 5 & 6 & 7 & 8 & 9 & 10 & 1\end{array}$

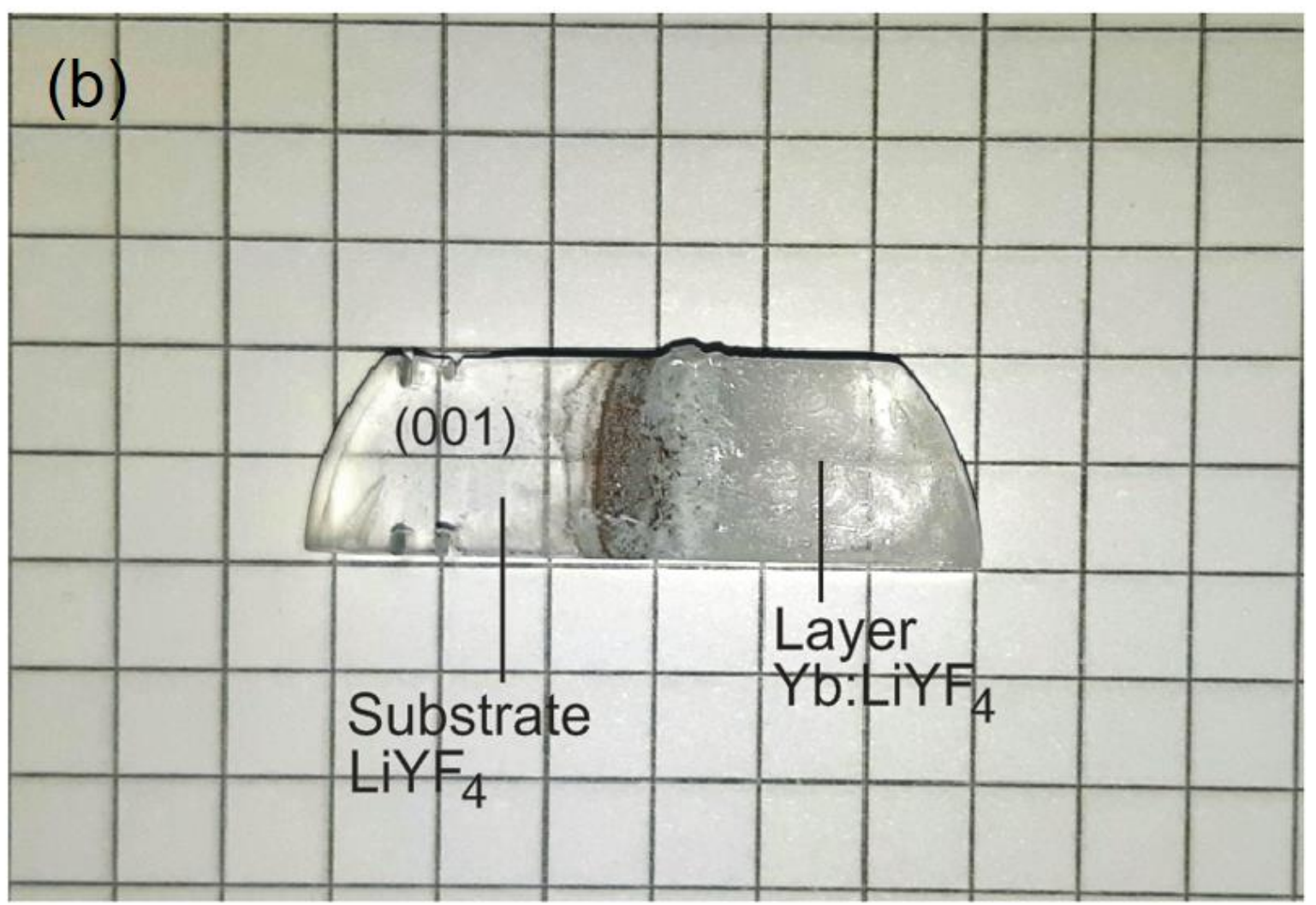



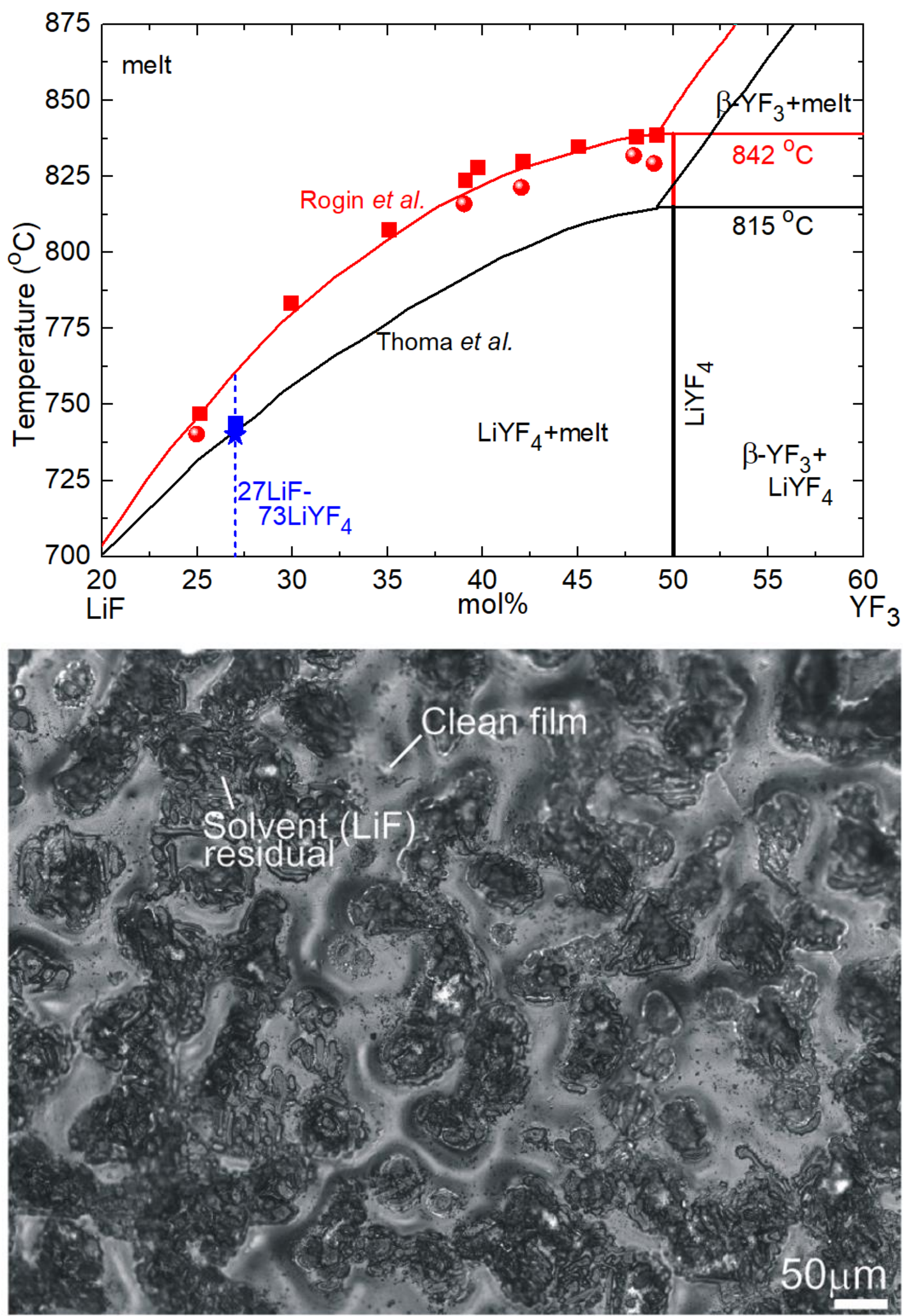

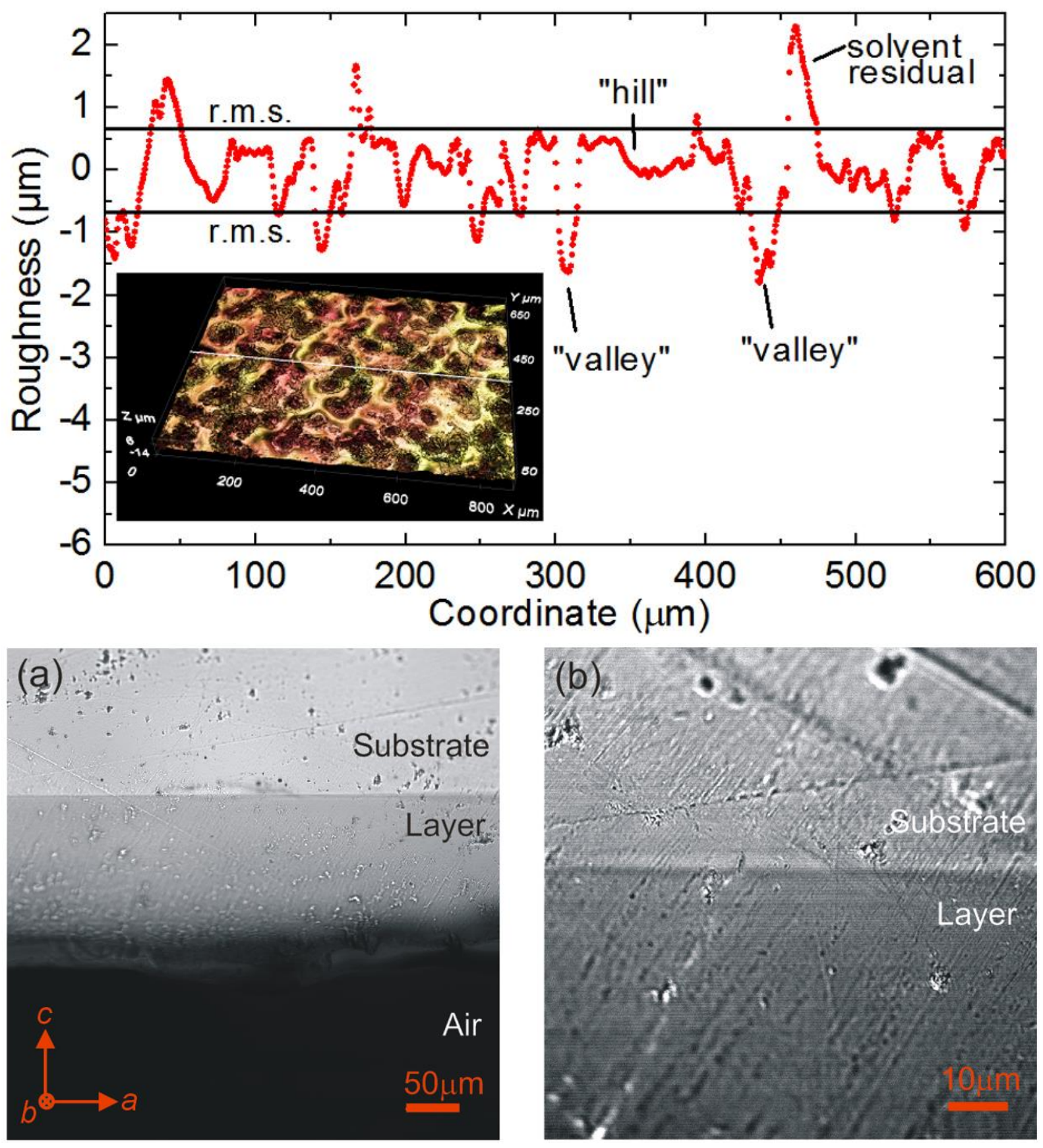

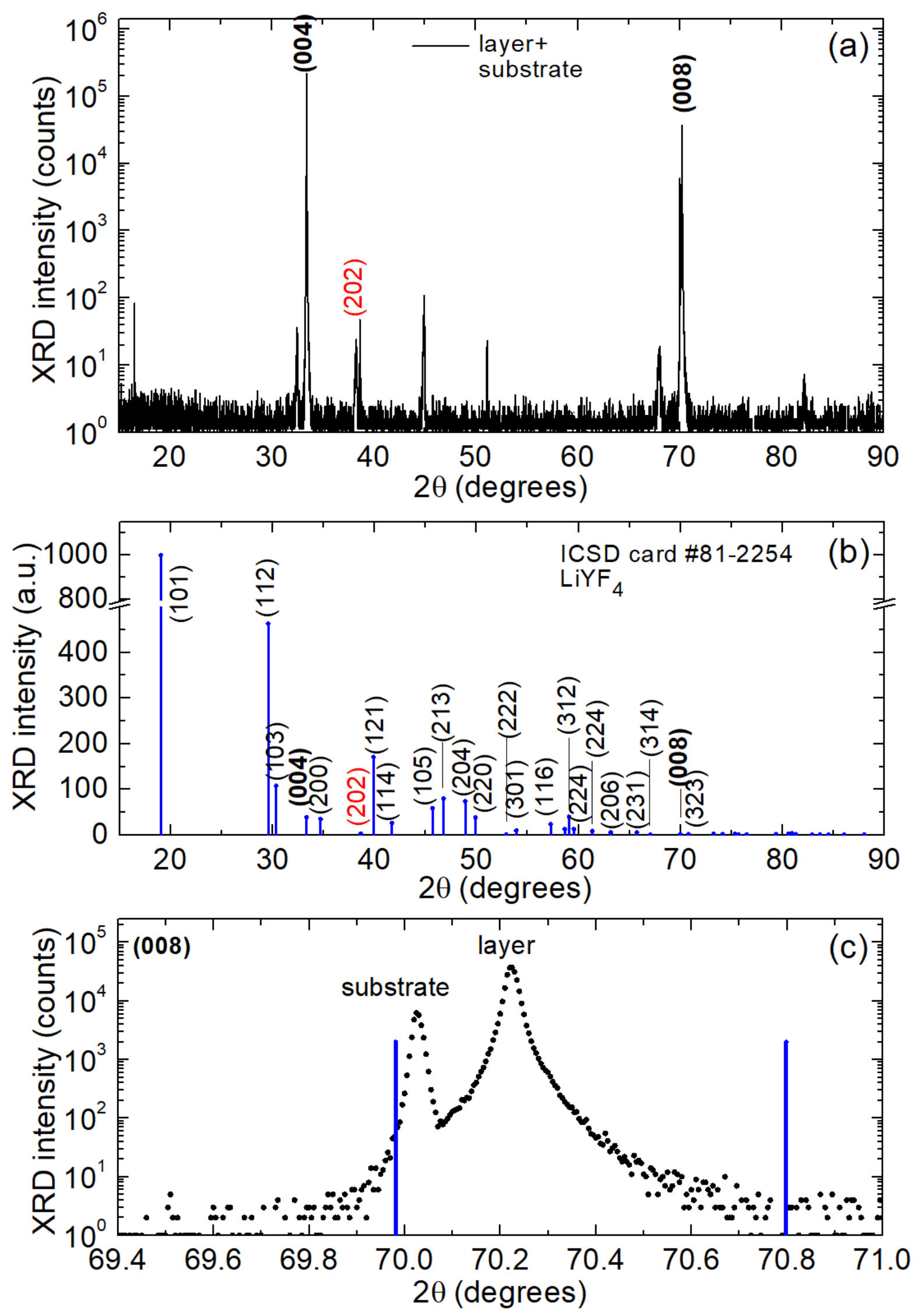

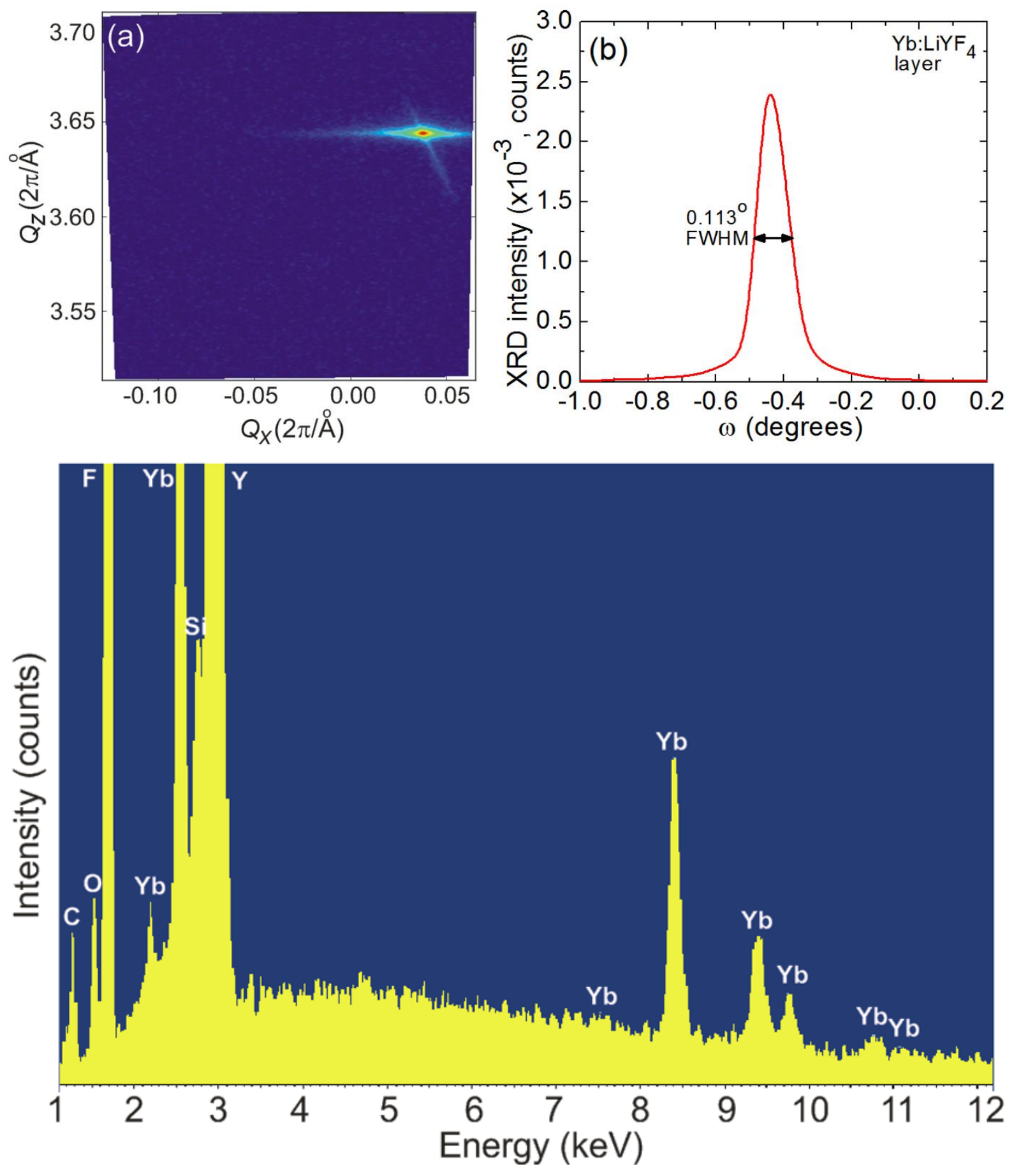

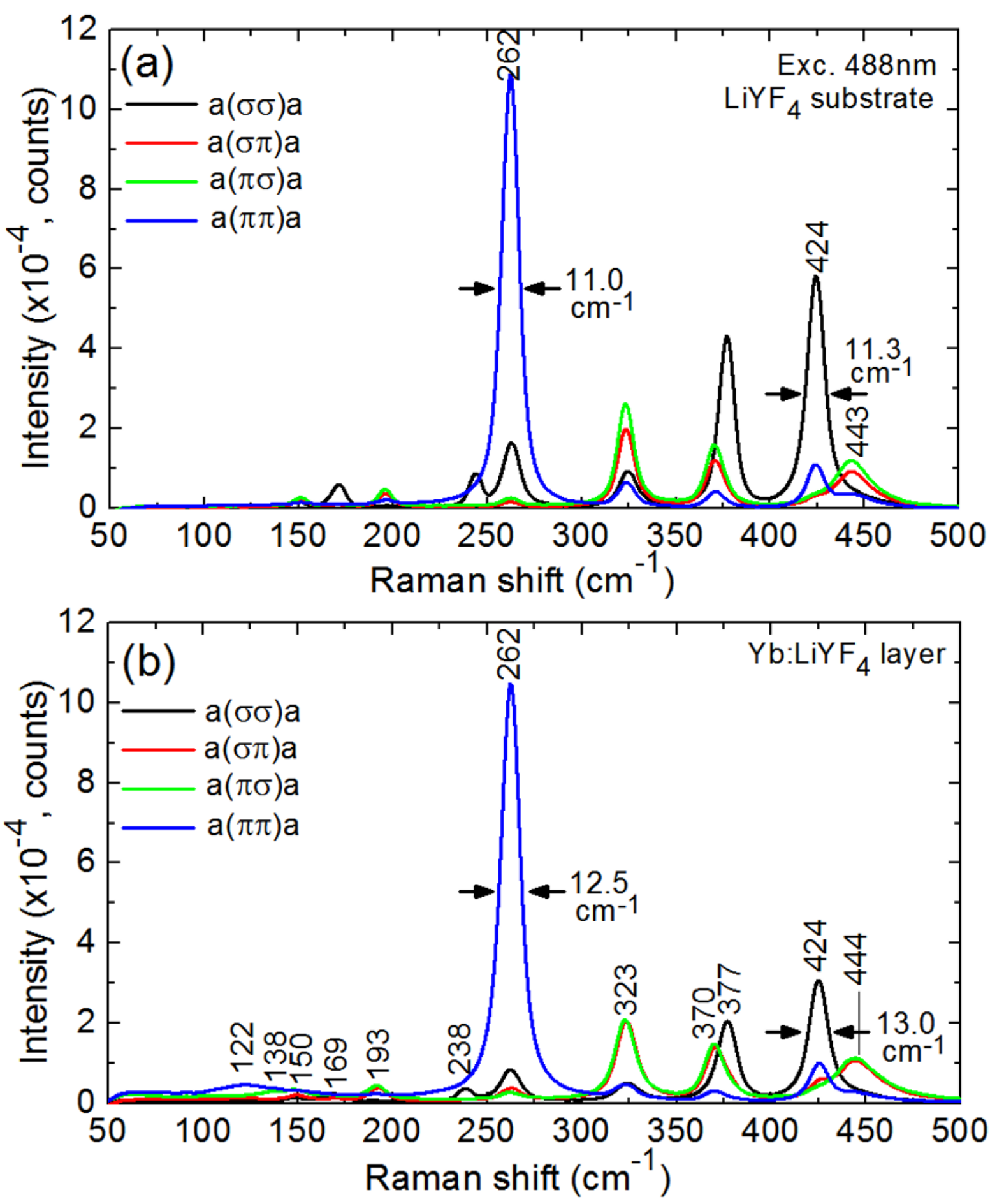

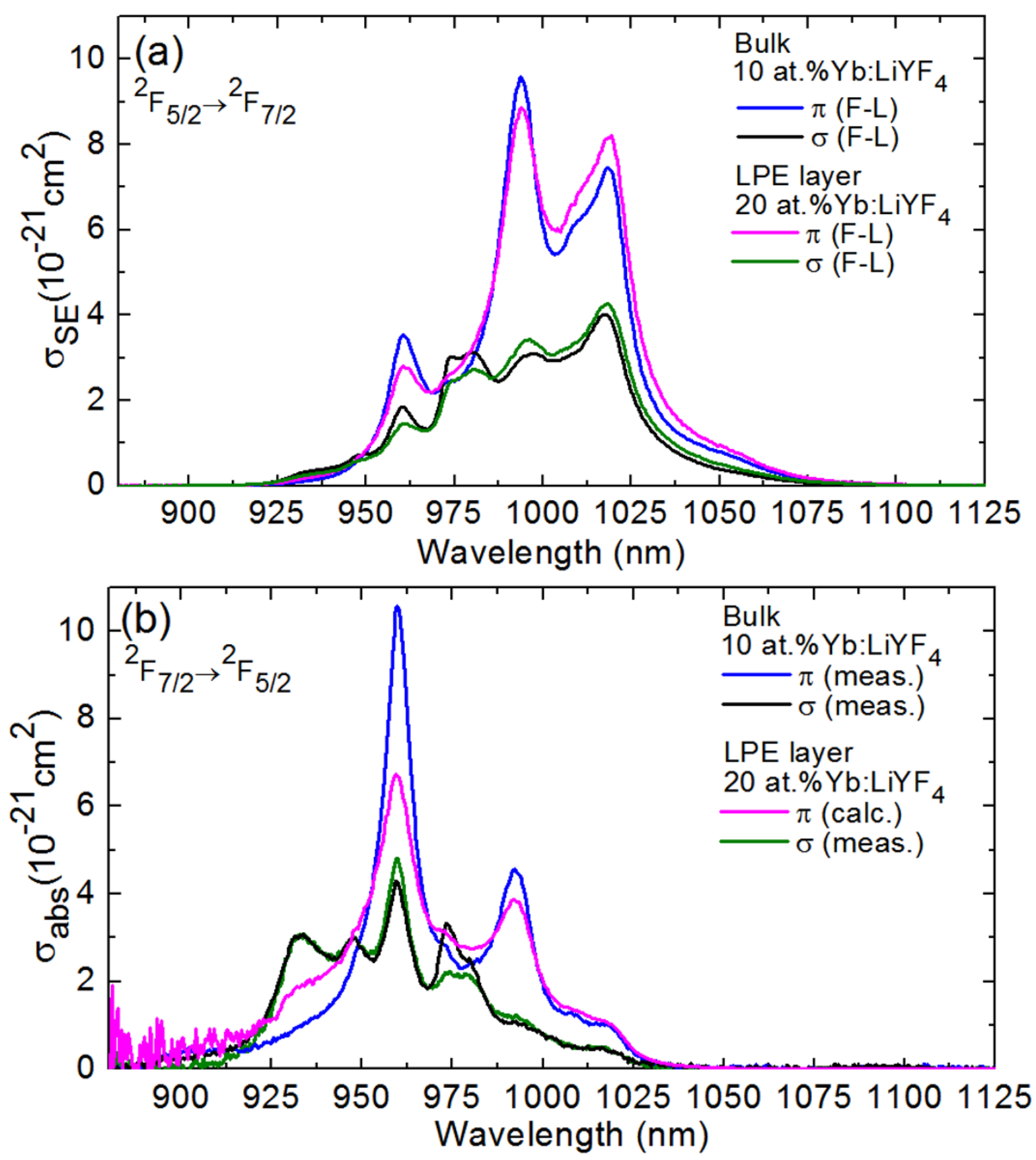

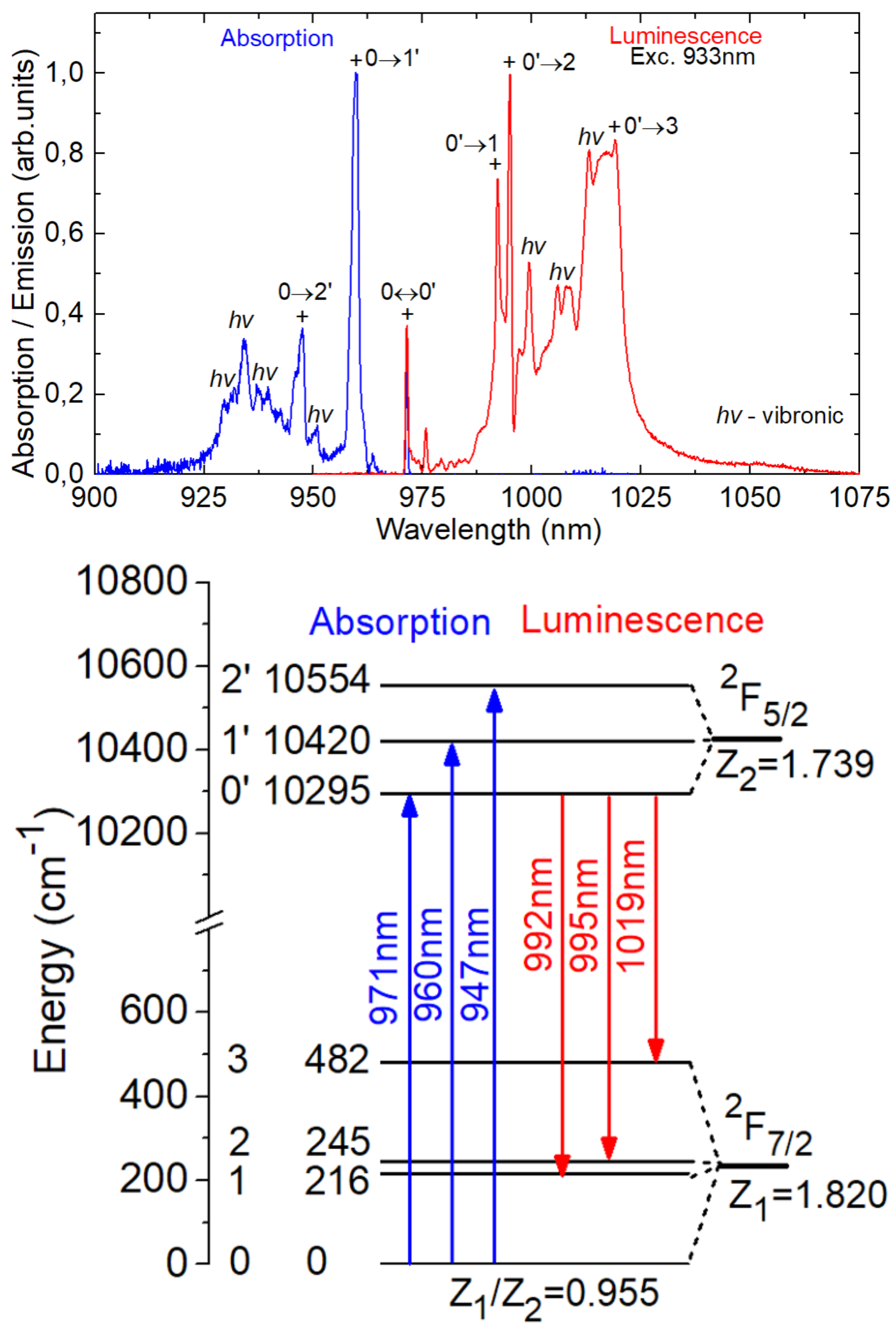

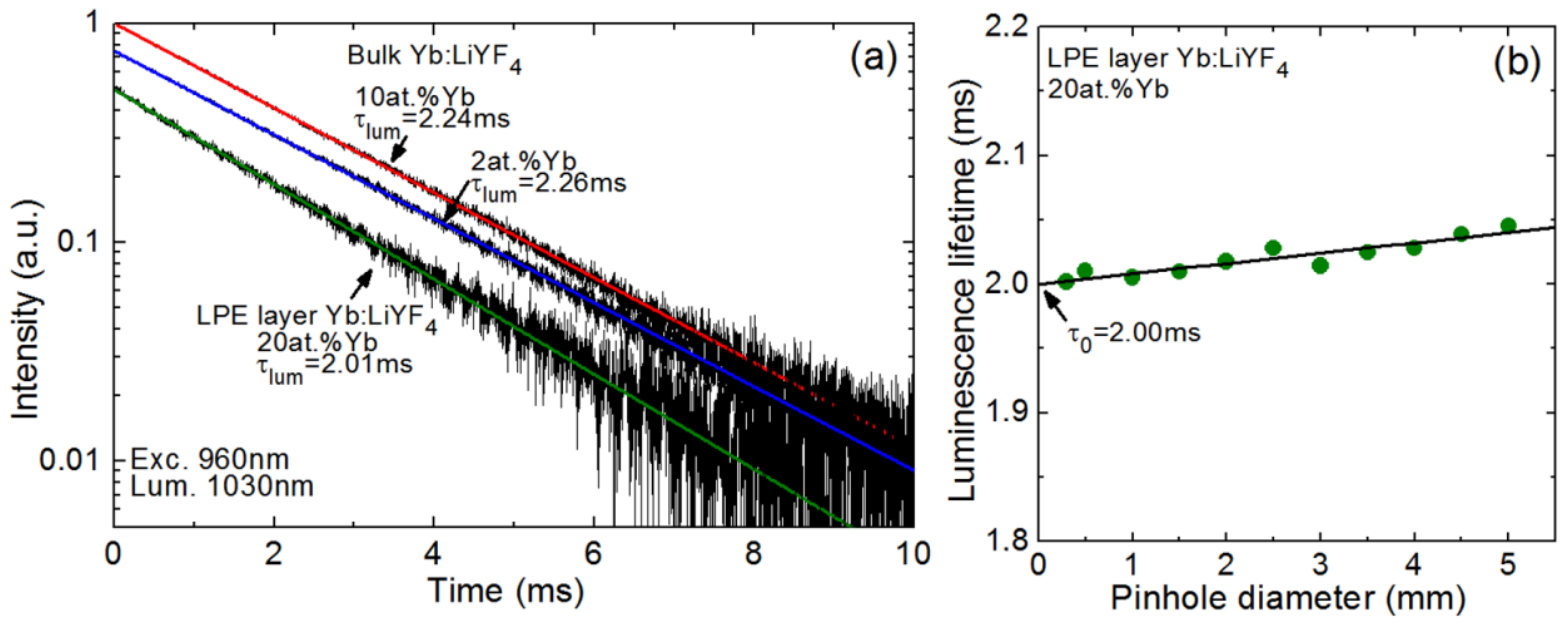